\title{
EXPERIMENTAL AND NUMERICAL STUDY ON MECHANICAL BEHAVIOR OF COMPOSITE GIRDERS UNDER HOGGING MOMENT
}

\author{
Weiwei $\operatorname{Lin}^{1}$ and Teruhiko Yoda ${ }^{2, *}$ \\ ${ }^{I}$ Assistant Professor, Department of Civil and Environmental Engineering, \\ Waseda University, Shinjuku-ku, Tokyo 169-8555, Japan \\ ${ }^{2}$ Professor, Department of Civil and Environmental Engineering, \\ Waseda University, Shinjuku-ku, Tokyo 169-8555, Japan \\ *(Corresponding author: E-mail: yoda1914@waseda.jp)
}

Received: 24 March 2012; Revised: 10 July 2012; Accepted: 13 July 2012

\begin{abstract}
In continuous steel-concrete composite structures, cracking of the concrete slab in the hogging bending moment region decreases the global stiffness of composite structures and reduces the effect of continuity, resulting in making the structural behaviors highly nonlinear even for low stress levels. Because of this, special consideration is necessary. The purpose of the present study is to investigate the effects of rubber-latex mortar and different types of shear connectors on inelastic behavior of composite girders subjected to hogging moment. Two overturned simply supported steel-concrete composite girders with different shear connectors such as Studs and Perfo-Bond Strips (PBLs) were tested under concentrated load in the mid-span. Based on the experimental observations, a three-dimensional FE model capable of analyzing the composite beams subjected to negative bending moment was built. Strength and load bearing capacity, sectional strain distribution and movement of composite neutral axis before and after cracking were observed in the test and compared with the numerical results, and the results predicted by this modeling method are in good agreement with those obtained from the tests. Research results indicate that the PBL connectors could slightly improve the rigidity of the composite girder under both the serviceability limit state and the ultimate limit state, while Stud specimens have relatively better mechanical behavior in regard to the initial crack and the "crack closure" of the test specimens. Besides, research results indicate that the current specifications such as AASHTO, JSCE, and EUROCODE-4 can provide appropriate values for ultimate strength of a composite girder under negative bending moment. Moreover, noise reduction, shear stud stiffness increase and the adhesion bonding effect of rubber-latex mortar on interface slip were confirmed in the tests.
\end{abstract}

Keywords: Steel-concrete composite girder, hogging moment, rubber-latex mortar coating, studs, PBLs

\section{INTRODUCTION}

In recent years, the composite steel and concrete structures are used extensively for construction of both building and bridge structures due to their benefits of combining the advantages of component materials and obtaining efficient lightweight structural members, not only for simply supported girders, but also for continuous composite girders. For simply supported composite beams, the ultimate loading capacity is usually dominated by either flexural or shear bearing capacity, which will be governed by the compressive strength of the concrete and tensile strength of the joist steel girder. However, for continuous composite girders or composite girders subjected to hogging moment, this condition may not be fully satisfied. Negative bending moment acting in the support regions of continuous composite beams generate tensile stresses in the concrete slab and compressive stresses in the lower steel profile. As a result, the mechanical behavior of these girders is strongly nonlinear even for low stress levels, due not only to the slip at the beam-slab interface, but also to cracking in the slab, which generally has shortcomings in view of durability and service life of the structures [1,2]. Therefore, special considerations for composite girders under negative bending moment are necessary. For this reason, experimental studies about inelastic behavior of composite girder under negative bending have been done widely. Special attentions were generally 
given to crack control methods [3, 4], failure modes [5, 6], and long-term behaviors [7] and so on. In addition, some numerical models were also created to simulate the composite girders under negative bending. Those numerical models keep a watchful eye on the effect of slip on the steel-slab interface [8,9], partial shear connection [10], or improved numerical methods [11].

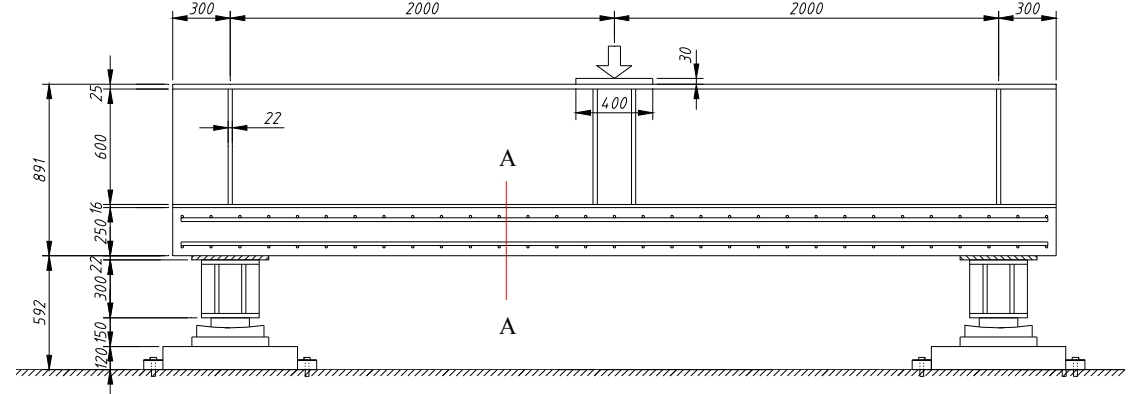

(a) Front Elevation

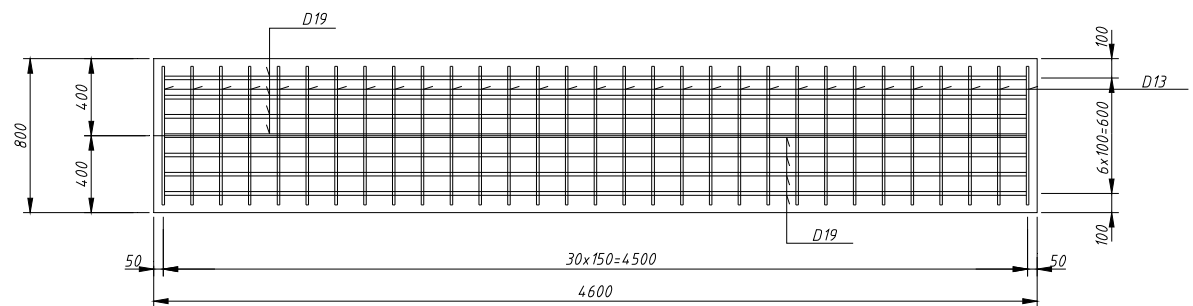

(c) Reinforcing Bars

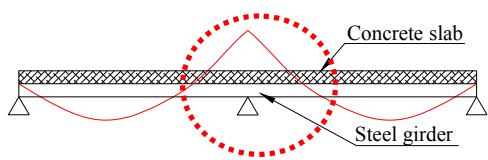

(e) Negative Moment Region in Continuous Composite Girder

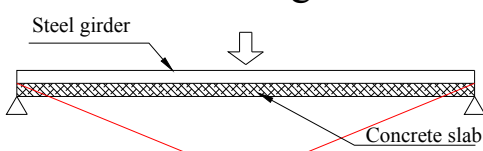

(f) Overturned Simply Supported Composite Girder

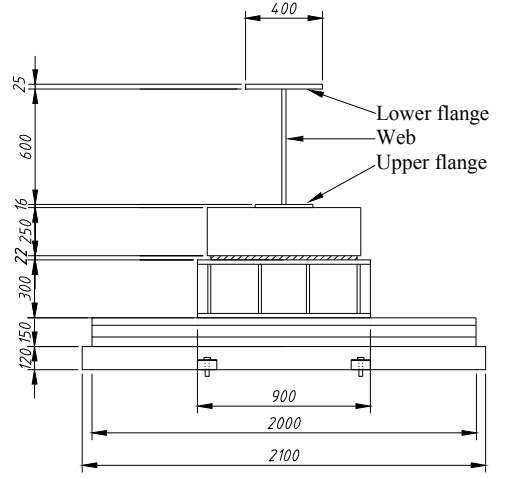

(b) Side Elevation

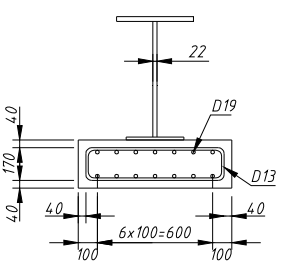

(d) Sectional View

Figure 1. Dimensions of Test Specimen

Table 1. Details of Test Specimens

\begin{tabular}{|c|c|c|c|c|c|c|}
\hline \multirow{2}{*}{ Specimen } & Connection & \multicolumn{2}{|c|}{ Shear connectors spacing(mm) } & Reinforcing bars spacing (mm) & Rubber-latex \\
& device & Longitudinal & Transverse & Longitudinal bars & Stirrup & spraying \\
\hline CBS & Stud & 150 & 100 & 100 & 150 & Yes \\
\hline CBP & PBL & 150 & 240 & 100 & 150 & Yes \\
\hline
\end{tabular}

Table 2. Rubber-Latex Mortar Spraying Details

\begin{tabular}{|c|c|c|c|}
\hline Details & \multicolumn{2}{|c|}{ Spraying thickness $(\mathrm{mm})$} & \multirow{2}{*}{ Spraying times } \\
\cline { 2 - 3 } Locations & CBS & CBP & 2 \\
\hline Top surface of upper flange & 7.7 & 6.6 & 2 \\
\hline Bottom surface of upper flange & 3.0 & 4.8 & 2 \\
\hline Web & 6.7 & 6.4 & 2 \\
\hline Shear connector & 2.1 & 6.7 & 2 \\
\hline Top surface of lower flange & 3.0 & 4.8 & 3 \\
\hline Bottom surface of lower flange & 5.0 & 7.0 & \\
\hline
\end{tabular}




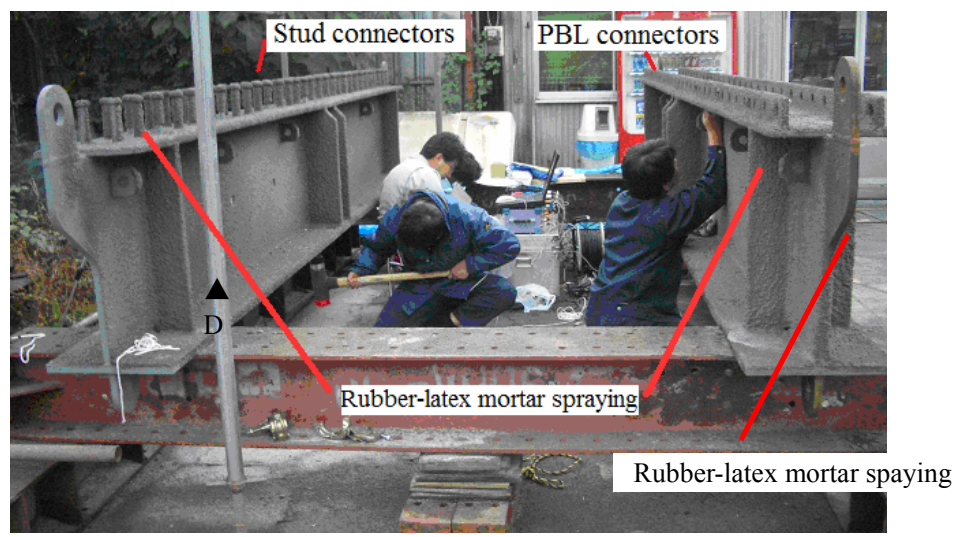

(a) Steel Girder and Shear Connectors

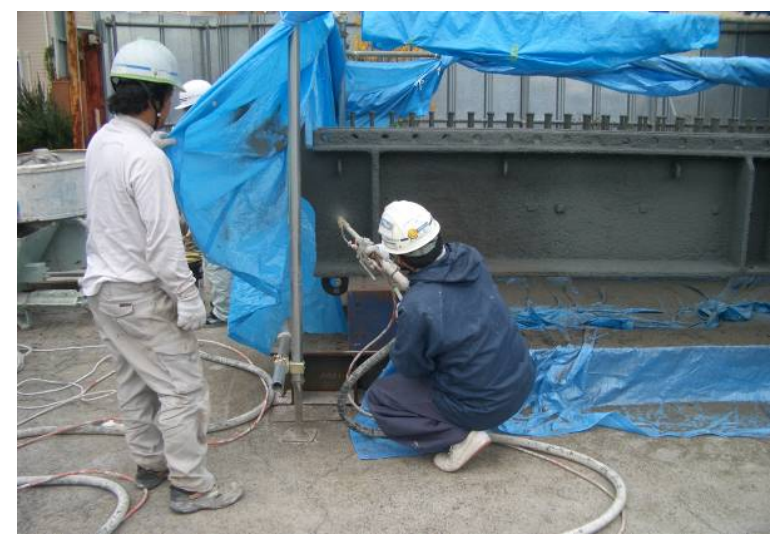

(b) Rubber-Latex Mortar Spaying Construction

Figure 2. Shear Connectors and Rubber-Latex Mortar Spaying

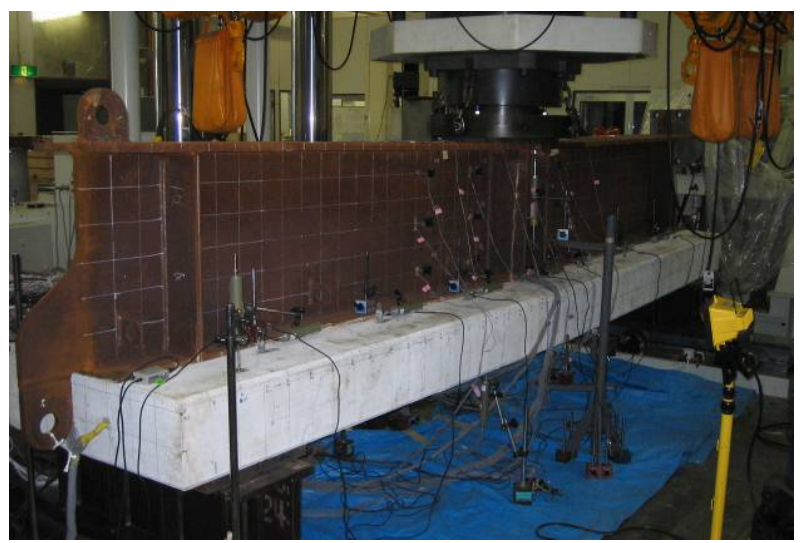

Figure 3. Static Loading Test Set-Up

Shear connectors, sometimes known generally as Perfo-Bond Strips (PBLs) or Nelson Studs, are used in steel-concrete composite structures. They act as reinforcing members, connecting the steel girder with the concrete slab. Stud and Perfo-Bond Strips (PBLs), generally known as flexible and rigid shear connectors, are most frequently-used shear connectors in steel-concrete composite girders. Current studies mainly pay attention to mechanical behavior of the shear connector itself, such as the ultimate load carrying capacity and load-deformation response. Recently, the effects of shear connectors on structural behavior of composite girders were performed by some researchers [4, 12, and 13].

Concrete and mortar, including SBR latex, shows various abilities especially in adhesion bonding, waterproofing, shock absorption and abrasion resistance. The rubber-latex mortar was used for steel 
structures to reduce the noise as well as the interface slip, enhance the integrity and improve the durability of the composite structures. Moreover, the composite structures with rubber-latex mortar coating are also reported to have the good impact resistance, weather resistance as well as the good constructability and operability behaviors. Some experimental studies were performed recently to study the effects of rubber-latex mortar on the mechanical behavior of composite structures [12, 13, and 14].

For this kind of background, this paper presents the experimental and numerical results of test composite girders subjected to negative bending, including the strain distribution at salient sections along the span and strain development process of reinforcements, load-displacement response, and load-carrying capacity as well as the interface slip distribution. The objective of the present study is to investigate the influence of rubber-latex mortar coating and to clarify the difference between Studs and PBLs on inelastic mechanical behavior of composite girders subjected to negative bending or support regions of continuous steel-concrete composite girders.

\section{EXPERIMENTAL PROGRAMME}

\subsection{Details of Test Specimens}

Two overturned simply supported steel-concrete composite beams CBS and CBP were tested under concentrated load in mid-span, which were used to simulate the support regions of continuous composite steel and concrete girder as shown in Figure 1 (e and f). CBS was designed with studs as shear connectors whilst CBP was designed with PBLs as shear connection devices. Each of the specimens was $4.6 \mathrm{~m}$ in length and was simply supported at a span of $4 \mathrm{~m}$. The concrete slab thickness was $250 \mathrm{~mm}$ with a width of $800 \mathrm{~mm}$. Vertical stiffeners were welded at supports, loading points to prevent shear buckling failure and crippling of the web before flexural failure. Different shear connectors, including $22 \mathrm{~mm}$ nominal diameter headed shear studs and $12 \mathrm{~mm}$ thickness PBLs were used to connect the concrete slab and the steel girder, and the composite section was designed as full shear connection according to JSCE specifications [15]. The typical geometry of test specimen is shown in Figure 1, and the detailed sectional properties were illustrated in Table 1. Besides, it is worth noting that upper flange, web and lower flange of steel girder are named as shown in Figure 1 (b). Moreover, rubber-latex mortar was sprayed on the surface of the steel girder, concrete slab and the shear connectors including PBLs and shear studs, as shown in Figure 2 and with details listed Table 2 .

\subsection{Instrumentation}

Measurement of strains in the reinforcements, steel girder and concrete slab were conducted by mean of electric resistance gauges at sections located at mid-span, $20 \mathrm{~cm}$ and $60 \mathrm{~cm}$ from the mid-span, respectively. Strain gauges were also employed at the root of the shear studs to measure the flexural strain during the loading process. Deflections and transverse deformations were measured by mean of deformation gauges at key sections. Since reaction supporting beams were set up at the ends, deflections were also measured at the end sections. Measurement of slips between the concrete slab and steel beams were also conducted by mean of deformation gauges, and the $\pi$-gauges for measuring the crack width on the concrete slab were also employed in the test. In addition, impact test was performed on the steel girder before the concrete casting to confirm the effect of rubber-latex mortar on noise reduction, and the accelerometers were arranged on the middle center of the web in the $1 / 4$ span section. 


\subsection{Test Set-up and Loading Procedure}

The experiment was performed in the Structural Laboratory of Waseda University. The 5000kN loading capacity equipment of "Two Axes Large-scale Apparatus used for Performance Evaluation of Structures" was used in the experiment to apply a point load in the mid-span of the overturned composite beams. The test specimen was supported by a roller system at two ends. The set-up for the steel-concrete composite girder test is illustrated in Figure 3. After the drying shrinkage had stabilized, pre-loading was applied to check the reliability of the measure equipment and the stability of the test specimen. The behavior of composite girders in elastic, cracking, and inelastic ranges was carefully observed through the static tests. The test girder was loaded in four cycles with the maximum loads of $200,400,700,1300 \mathrm{kN}$ before the ultimate load was reached. For unloading process, the load was removed at the calculated initial cracking load $(200 \mathrm{kN})$ and at the stationary cracking load $(700 \mathrm{kN})$ to check the cracking of the concrete slab [16]. The loading was terminated when either the maximum stroke of the jack was reached or when the load level of the test specimen dropped significantly.

\section{NUMERICAL SIMULATION OF EXPERIMENT}

\subsection{Model Building}

The modeling of each numerical model was carried out in three dimensions by using the finite-element method and the DIANA software, as shown in Figure 4. Solid elements, shell elements, spring elements were used to simulate the concrete slab, steel girder and PBLs, stud connectors respectively. For each stud, three springs were employed to simulate the shear and axial forces in three directions. Re-bar elements were used for modeling reinforcing bars in the concrete slab, and perfect bond between reinforcements and surrounding concrete was assumed. $3 \mathrm{~cm}$ thickness loading plate was also modeled by using shell element. In order to predigest complicated numerical simulation, the rubber-latex mortar was not modeled as the separate structural member but considered as special treatment for the steel-slab interface and it will enhance the bond stiffness as well as the bond strength of the steel-slab interface. Therefore, with the purpose of accounting for the slip and the composite action between concrete slab and steel girder, interface elements that considering the adhesion bonding effects of rubber-latex mortar were employed in the numerical models. Rigid supporting plate and simplified line support were employed to simulate the simply supported boundary conditions.

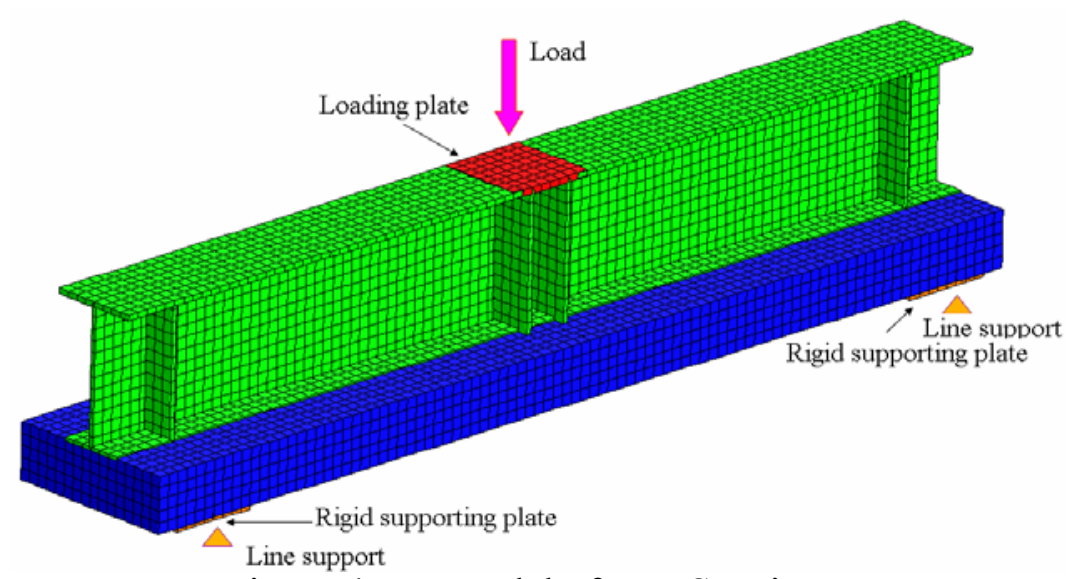

Figure 4. FE Model of Test Specimen 
Table 3. Mix Proportion of Concrete

\begin{tabular}{|c|c|c|c|c|c|c|c|}
\hline Specimen & $\begin{array}{c}\text { Design strength } \\
\left(\mathrm{N} / \mathrm{mm}^{2}\right)\end{array}$ & $\begin{array}{c}\text { Aggregate } \\
\text { size }(\mathrm{mm})\end{array}$ & $\begin{array}{c}\text { Slump } \\
(\mathrm{mm})\end{array}$ & $\begin{array}{c}\text { W/C } \\
(\%)\end{array}$ & $\begin{array}{c}\text { Air } \\
(\%)\end{array}$ & $\begin{array}{c}\text { Unit cement } \\
\left(\mathrm{kg} / \mathrm{m}^{3}\right)\end{array}$ & $\begin{array}{c}\text { Unit salinity } \\
\left(\mathrm{kg} / \mathrm{m}^{3}\right)\end{array}$ \\
\hline CBS \& CBP & 27 & $<20$ & $80 \pm 25$ & $<55$ & $4.5 \pm 1.5$ & $>230$ & $<0.3$ \\
\hline
\end{tabular}

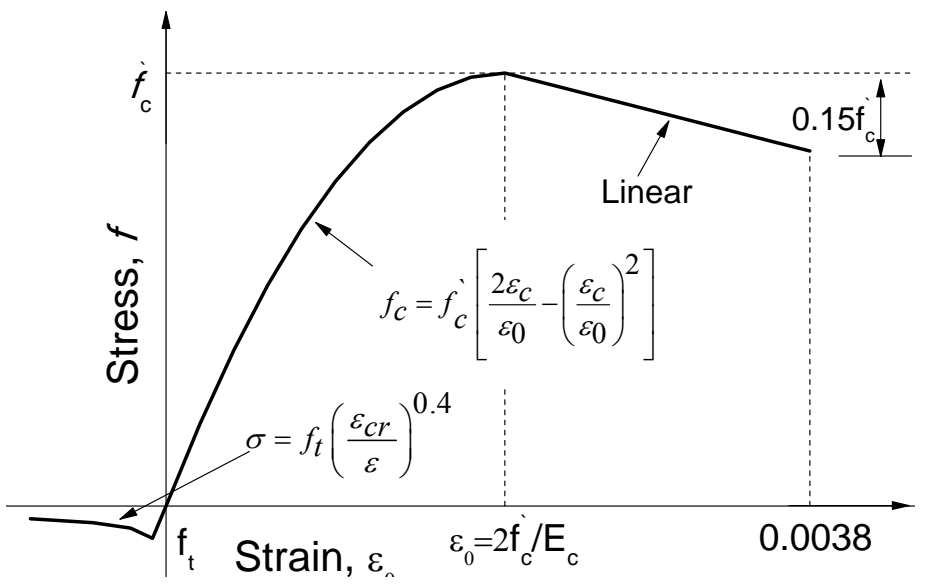

Figure 5. Stress-Strain Curve for Concrete

\subsection{Material Properties}

\subsubsection{Concrete}

Material property of concrete is determined from material test. Mix proportion of concrete for test specimen was illustrated in Table 3. The nominal concrete compressive strengths achieved after twenty-eight days of curing for CBS and CBP was $29.1 \mathrm{~N} / \mathrm{mm}^{2}$. Tensile strength of the concrete was calculated according to Eq. (1) suggested by JSCE (2002), in which the $f_{t}$ and $f_{c}^{\prime}$ denote tensile and compressive strengths of concrete, respectively. The often quoted stress-strain curve due to Hognestad [17, 18] was employed to simulate the compression behavior of concrete, shown in Figure 5. Experimental tension-stiffness curve proposed by Nakasu et al. [19] is used in the numerical analysis to reflect the softening of concrete due to crack.

$f_{t}=0.23 f_{c}^{\prime 2 / 3}$

\subsubsection{Structural steel and reinforcing bars}

The uniaxial stress-strain relationships for structural steel and reinforcing bars shown in Figure 6 were adopted in numerical models based on the material tests. Three steel beam coupons were cut out from different components of the upper flange, web, lower flange and PBL with different nominal thickness of $16,22,25$ and $12 \mathrm{~mm}$ respectively, and the tensile tests were performed. Fourteen reinforcing bars of D19 nominal diameter were used for two layers as longitudinal reinforcing bars in the concrete slabs, whilst D13 stirrup reinforcing bars were used as torsional reinforcement with a nominal diameter of $13 \mathrm{~mm}$. Multi-linear stress-strain relationships for structural steel and rebar used in the numerical models are shown in Figure 6(b). 


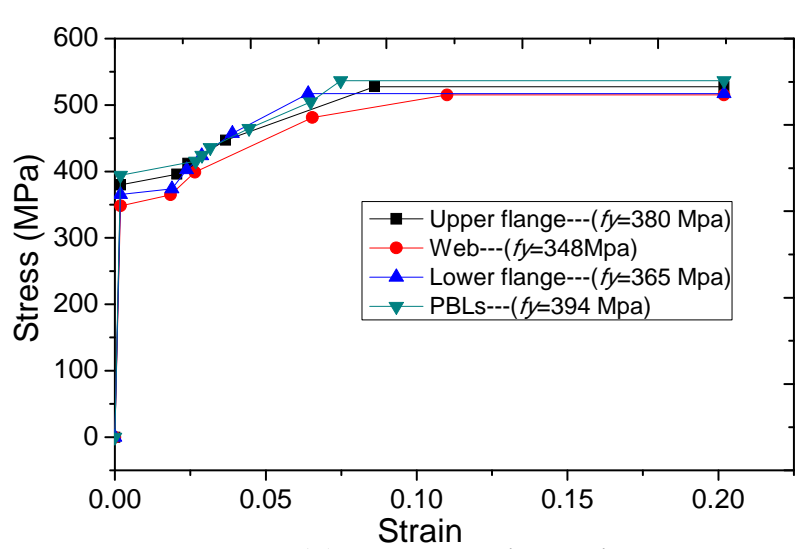

(a) Structural Steel

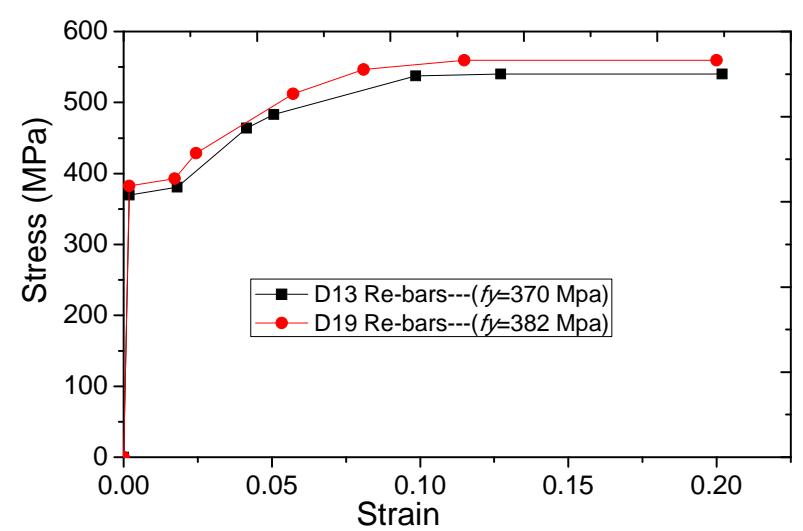

(b) Reinforcing Bars

Figure 6. Multi-Linear Stress-Strain Relationship for Structural Steel and Rebar

\subsubsection{Shear connectors}

Studs and PBL shear connectors during the concrete casting are shown in Figure 7. In the test specimen, it was intended that the shear connections were installed to achieve full shear connections, which means the shear connectors should be still reliable even when the test specimens are in the ultimate state. Therefore, the present study is limited to full shear connection specimens (or the shear degree is larger than 1.0).

In the numerical study, the shear studs were modeled by $3 \mathrm{D}$ nonlinear spring elements. For each stud, three springs are used, two in horizontal direction and one in vertical direction. A previous study [20] shown that the shear force-slip curve is generally nonlinear and it is reasonable to use a nonlinear spring in modeling the mechanical behavior of the connectors. The constitutive relationship of the spring is given by Eq. (2) suggested by Ollgaard et al. [21] and illustrated in Figure 8, in which the ultimate shear force loading capacity of studs was specified by JSCE specifications [15], shown as Eq. (3).

$Q=Q_{u}\left(1-e^{-0.7 S}\right)^{0.4}$

$$
Q_{u}=\min \left(\begin{array}{c}
\left(31 A_{s s} \sqrt{\left(h_{s s} / d_{s s}\right) f_{c d}^{\prime}}+10000\right) / \gamma_{b} \\
A_{s s} f_{s s} / \gamma_{b}
\end{array}\right)
$$

where $S$ : slip of the shear stud (mm), $A_{s S}$ : area of the shank of the stud $\left(\mathrm{mm}^{2}\right), d_{s s}$ : diameter of the shank of the stud $(\mathrm{mm}), h_{s s}$ : height of the stud $(\mathrm{mm}), f_{c d}$ : design compressive strength of concrete $\left(\mathrm{N} / \mathrm{mm}^{2}\right)\left(=f_{c k}^{\prime} / \gamma_{c}\right), f_{c k}$ : the characteristic compressive strength of concrete $\left(\mathrm{N} / \mathrm{mm}^{2}\right), f_{s s}$ : design tensile strength of the stud $\left(\mathrm{N} / \mathrm{mm}^{2}\right)\left(=f_{s k} / \gamma_{s}\right), f_{s k}$ : characteristic tensile strength of the stud $\left(\mathrm{N} / \mathrm{mm}^{2}\right)$, $\gamma_{c}$ : material factor of concrete $(=1.3), \gamma_{s}$ : material factor of stud $(=1.0), \gamma_{b}$ : member factor $(=1.3)$. 


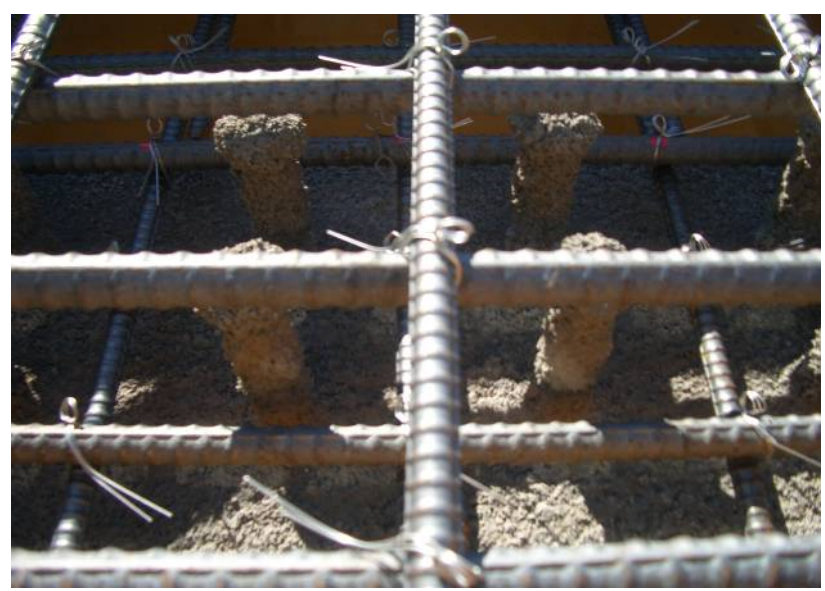

(a) Stud Connectors

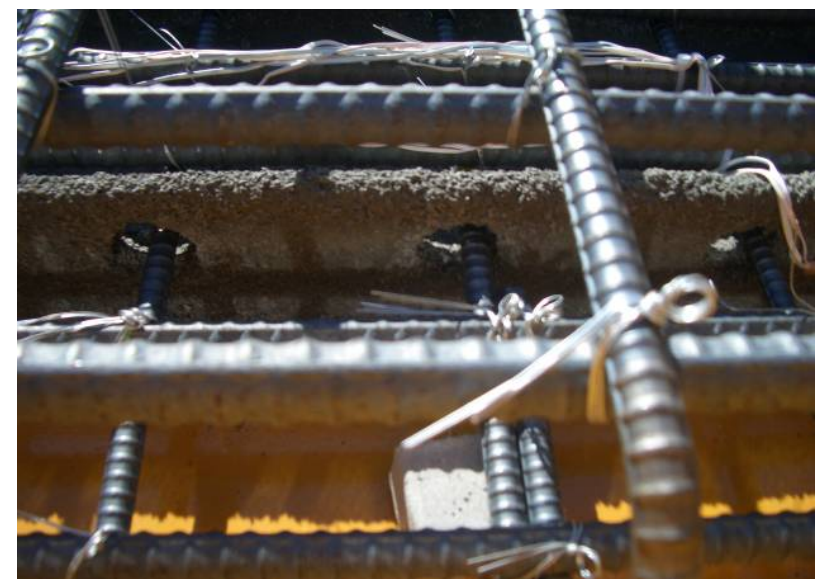

(b) PBL Connectors

Figure 7. Shear Connectors during the Concrete Casting

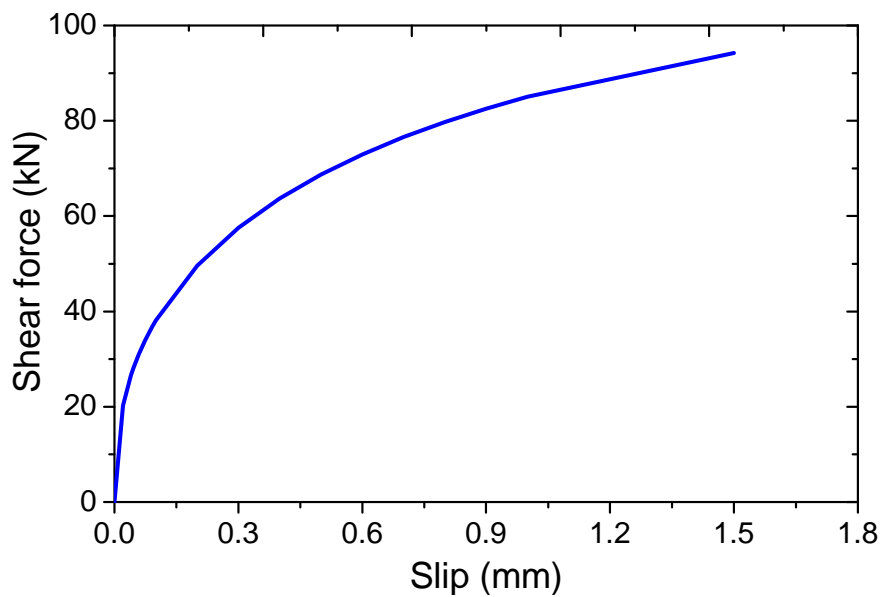

Figure 8. Constitutive Relation of Shear Stud

Several authors, such as Ahna et al. [22], Al-Darzi et al. [23], Iwasaki et al. [24], Machacek and Studnika [25], Medberry and Shahrooz [26], Ushijima et al. [27], and Valente and Cruz [28] have recently studied the behaviour of the PBL connector. And the resistance capacity of PBL shear connectors was proposed by JSCE (2007) as follows [15]

$Q_{u}=\left[1.45\left\{\left(d^{2}-\phi_{s t}^{2}\right) f_{c d}^{\prime}+\phi_{s t}^{2} f_{s t}\right\}-106.1 \times 10^{3}\right] / \gamma_{b}$ 
with the application limit in the following:

$73.2 \times 10^{3}<\left(d^{2}-\phi_{s t}^{2}\right) f_{c d}^{\prime}+\phi_{s t}^{2} f<488 \times 10^{3}$

where $\mathrm{d}$ is the diameter of the Perfo-Bond strip holes $(\mathrm{mm}), f_{c d}^{\prime}$ is the design concrete compressive strength $\left(\mathrm{N} / \mathrm{mm}^{2}\right), \phi_{s t}$ and $f_{s t}$ are the diameter $(\mathrm{mm})$ and tensile strength $\left(\mathrm{N} / \mathrm{mm}^{2}\right)$ of re-bar. The member factor $\gamma_{\mathrm{b}}$ can be taken as 1.3.

However, the previous mentioned tests also proved that the PBL shear connector has relatively larger stiffness and smaller slip during the whole loading process (especially when reinforcement pass through the holes, like the present PBL specimen as shown Figure 7(b)) in comparison with the other types of shear connectors. Thus, in order to predigest complicated calculation, the PBL connector was simulated by using shell element and perfect bond was assumed between PBLs and surrounding concrete. The goal of the numerical analysis is not to get exact resemblance between modeled and measured results on the complicated local behavior on the shear connectors, but to model the global behavior of the test specimens.

Table 4. Material Property of Rubber-Latex Mortar

\begin{tabular}{|c|c|}
\hline Appearance & oyster white \\
\hline Solid content & $45.0 \pm 1.0 \%$ \\
\hline PH & $9 \pm 1$ \\
\hline Viscosity $\left(20^{\circ} \mathrm{C}\right)$ & $<200 \mathrm{mPa}+\mathrm{S}$ \\
\hline Mean specific gravity & $1.00 \pm 0.05$ \\
\hline Compressive strength & $32.3 \mathrm{~N} / \mathrm{mm}^{2}$ \\
\hline Elastic modulus & $21 \mathrm{kN} / \mathrm{mm}^{2}$ \\
\hline
\end{tabular}

\subsubsection{Rubber-latex mortar}

Styrene-Butadiene-Rubber (SBR) is a synthetic rubber copolymer consisting of styrene and butadiene. It has good abrasion resistance and good aging stability when protected by additives. The rubber-latex mixing with SBR was applied for both CBS and CBP, and its material properties were illustrated in Table 4. As mentioned above, the rubber-latex mortar was not considered as the separate structural member in the numerical analysis, but considered as the potential material for increasing the bond stiffness and strength of the steel-slab interface.

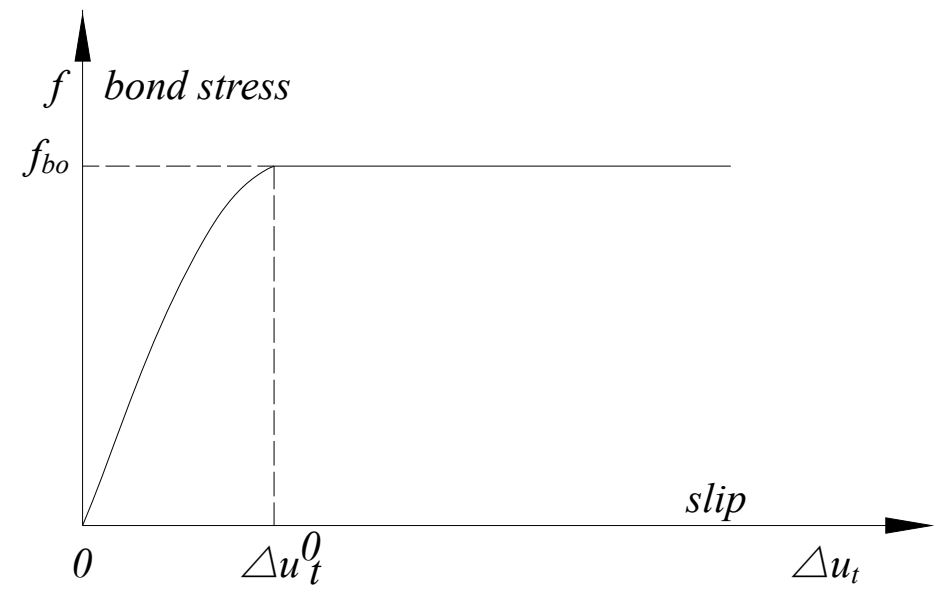

Figure 9. Material Properties of Interface 


\subsubsection{Composite action or interface}

In order to account for the composite action between steel girder and concrete slab, the interface element was used in the numerical analysis. And the bond-friction interface model suggested by Okada et al. [29] was employed in this study, as shown in Figure 9 and Eq. (5)-(6). As can be seen, constant bond or friction stress is supposed after breaking of the chemical bond on the steel-slab interface, which is developed from Dörr's bond-slip model [30] and has been verified by the previous push-out tests as well as numerical studies.

$$
\begin{aligned}
& 0 \leq \Delta u_{t} \leq \Delta u_{t}^{0}: \\
& f_{\text {tan }}=\frac{f_{b o}}{1.9}\left(5\left(\frac{\Delta u_{t}}{\Delta u_{t}^{0}}\right)-4.5\left(\frac{\Delta u_{t}}{\Delta u_{t}^{0}}\right)^{2}+1.4\left(\frac{\Delta u_{t}}{\Delta u_{t}^{0}}\right)^{3}\right) \\
& \Delta u_{t} \geq \Delta^{0} u_{t}: \\
& f=f_{b o}
\end{aligned}
$$

The maximum bond stress $f_{b o}$ is taken as $2.4 \mathrm{~N} / \mathrm{mm}^{2}$ by considering the adhesion bonding effects of rubber-latex mortar $[12,13]$. Concerning the corresponding slip to the peak bond stress, $0.06 \mathrm{~mm}$, this is the standard value of Dörr's model as well as Okada's model.

\section{RESULTS AND DISCUSSION}

\subsection{Strength and Deformation Response}

Totally 12 deformation gauges were employed for measurement of vertical displacement. The load-displacement curves obtained from the numerical analyses were compared with the experimental data as shown in Figure 10. Both numerical and experimental displacements are taken from the vertical deflection at the bottom mid-point of the composite beam, which is the bottom point of the concrete slab (Point D in Figure 1(a)). The loads corresponding to the theoretical yield and full plastic moments are plotted as the horizontal lines indicated by $P_{y}$ and $P_{p}$, respectively. The ultimate pure bending moments, $\mathrm{M}_{\mathrm{u}, \mathrm{t}}$ is to be calculated following the procedure for computing the plastic bending moment of composite sections under negative moment specified in Appendix D6.1 of AASHTO LRFD,2007[31].

It is found that in the linear region, the load-displacement curves from numerical studies agree well with the measured results. However, in the nonlinear region after girder yielding, the rigidity of FE model is a little bit stronger than the test girder. This is presumably because the residual stress is not considered in the finite element analysis, which may result in slightly larger stiffness of FE model than that of the test girder. And also, the present modeling method for shear connectors assumes the perfect bond between PBL connectors and concrete. At the final stage, the concrete can not sustain any increase in applied loading and eventually fails by through crack in the mid-span. The numerical results and experimental results are summarized and compared in Table.5. 
Table 5. Loading Capacity of the Test Specimens

\begin{tabular}{|c|c|c|c|c|c|c|c|c|c|c|}
\hline $\begin{array}{c}\text { Specimen } \\
\text { No }\end{array}$ & \multicolumn{3}{|c|}{$\begin{array}{c}\text { Initial cracking moment } \\
(\mathrm{kN} \cdot \mathrm{m})\end{array}$} & \multicolumn{2}{|c|}{$\begin{array}{c}\text { Yielding moment } \\
(\mathrm{kN} \cdot \mathrm{m})\end{array}$} & $\begin{array}{c}\text { Crack closure moment } \\
(\mathrm{kN} \cdot \mathrm{m})\end{array}$ & \multicolumn{2}{|c|}{$\begin{array}{c}\text { Ultimate bending moment } \\
(\mathrm{kN} \cdot \mathrm{m})\end{array}$} \\
\cline { 2 - 12 } & $\mathrm{M}_{\mathrm{c}, \mathrm{e}}$ & $\mathrm{M}_{\mathrm{c}, \mathrm{t}}$ & $\mathrm{M}_{\mathrm{c}, \mathrm{f}}$ & $\mathrm{M}_{\mathrm{y}, \mathrm{e}}$ & $\mathrm{M}_{\mathrm{y}, \mathrm{t}}$ & $\mathrm{M}_{\mathrm{y}, \mathrm{f}}$ & $\mathrm{M}_{\mathrm{c}, \mathrm{c}}$ & $\mathrm{M}_{\mathrm{u}, \mathrm{e}}$ & $\mathrm{M}_{\mathrm{u}, \mathrm{t}}$ & $\mathrm{M}_{\mathrm{u}, \mathrm{f}}$ \\
\hline CBS & 220 & 247 & 260 & 2702 & 2000 & 3100 & 3500 & 3801 & 3104 & 3720 \\
\hline CBP & 120 & 247 & 224 & 2505 & 2000 & 3260 & 3203 & 3999 & 3104 & 3900 \\
\hline
\end{tabular}

Note: $\mathrm{M}_{\mathrm{c}, \mathrm{e}}, \mathrm{M}_{\mathrm{c}, \mathrm{t}}$ and $\mathrm{M}_{\mathrm{c}, \mathrm{f}}=$ Initial cracking bending moment from experiments, theoretical calculation and numerical values; $\mathrm{M}_{\mathrm{y}, \mathrm{e}}, \mathrm{M}_{\mathrm{y}, \mathrm{t}}$ and $\mathrm{M}_{\mathrm{y}, \mathrm{f}}=$ Yielding moment from experiments, theoretical calculation and numerical values; $\mathrm{M}_{\mathrm{c}, \mathrm{c}}=$ Crack closure bending moment from experiments; $\mathrm{M}_{\mathrm{u}, \mathrm{e}}, \mathrm{M}_{\mathrm{u}, \mathrm{t}}$ and $\mathrm{M}_{\mathrm{u}, \mathrm{f}}=$ ultimate bending moment from experiments, theoretical calculation and numerical calculation, respectively.

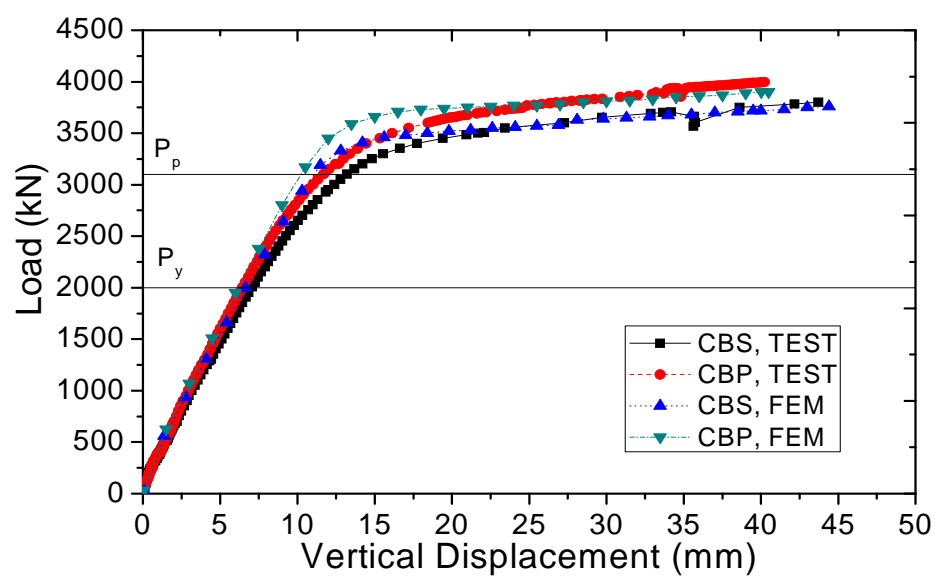

Figure 10. Load-Deflection Relationship

The initial cracking load calculated with reference to the slab exhibiting maximum negative moment of composite section under elastic state has been estimated to be $247 \mathrm{kN}$ for CBS and CBP, were close to numerical results but larger than experimental values. It seems to indicate that the initial cracking load is very small for composite beams under negative bending moment and thus making the structural behavior highly nonlinear even for very low stress levels. Besides, experimental girder yielding moment seems larger than theoretical values but smaller than those of numerical results, which might be caused by the neglection of concrete slab in theoretical calculation and perfect bond assumption on rebar-concrete interface in numerical simulation. Furthermore, a phenomenon of "crack closure" was observed in the tests and the corresponding loads were given, and the details will be discussed below. Regarding to the ultimate bending moment, as strain hardening of the steel girder and reinforcing bars was not considered in the theoretical analysis, resulting in that the experimental results was approximate to numerical results but much larger than the theoretical values. However, as the "crack closure" load is a little larger but relatively close to the theoretically ultimate load, current specifications can provide appropriate values in regard to the ultimate strength of a composite girder under negative bending moment. Moreover, comparison of load-deformation response of each specimen indicates that the displacement of CBP becomes a little less at around $1000 \mathrm{kN}$ than those of CBS, which is presumably because the PBL dowels affect the rigidity of the entire girder when cracking has progressed to a certain extent.

In addition, comparison between the numerical and experimental results of CBP and CBS also indicates that the initial cracking and crack closure moments of PBL specimen are much smaller in comparison with those of Stud specimen. It seems to demonstrate that the PBL connectors could be helpful to increase the girder stiffness and the ultimate loading capacity, but composite beams using studs as shear connectors have better mechanical behavior in regard to concrete cracking. This is presumably because the flexible behavior of studs is profitable for internal force and deformation redistribution. Besides, by comparison with the previous test results that without rubber-latex 
mortar, there is no obvious effects of rubber-latex mortar coating on the loading capacity, deformation behavior, or the failure modes of composite girders subjected to hogging moment [32].

\subsection{Composite Neutral Axes}

Figure 11 illustrates the movement of sectional neutral axis in both linear and nonlinear stage for test specimens. During testing, the sectional strain was measured in five characteristic sections located at span center, 60 and $20 \mathrm{~cm}$ from the span center respectively. In order to avoid the effect of $30 \mathrm{~mm}$ thickness loading plate, sectional strains were generated and compared with the experimental values on section A-A shown in Figure 1. Numerical strain results of steel and concrete elements were generated and compared with the measured strain values of the steel and the reinforcement from the tests. Elastic neutral axis (ENA) and plastic neutral axis (PNA) according to AASHTO LRFD (2007) [31] were given to make a comparison with the movement of the composite neutral axis of each test specimen.

It is observed that the strain distribution was linear for steel-concrete composite beams during the early stage of the tests, as shown in Figures 12 and 13. However, with the load increase, the strain distribution of the reinforcement has exhibited a different curvature compared with the strain distribution of the steel beam. Due to the presence of interface slip and the crack of the concrete slab, the plane cross-section assumption is not satisfied and the strain distribution difference could be produced between different portions of steel girder, concrete and the reinforcing bars. Furthermore, the movement of composite neutral axis can be divided into three stages, as shown in Figure 11. Firstly, when sectional bending moment is smaller than the cracking bending moment, the composite neutral axis is similar to the calculated elastic neutral axis. However, the test results show that the first stage is relatively small for composite girders subjected to negative bending moment. This is presumably because of the negative bending moment as well as the initial cracks in the test specimens, which will cause the structural behavior of composite girders highly nonlinear and the movement of composite neutral axis even when the load is relatively small. With the load increase, the composite neutral axis changes expeditiously and move towards the plastic neutral axis, which might be caused by the development of the cracks in the concrete slab and can be treated as the second stage. In the third stage, with the load increase the crack on the concrete slab becomes stable and the cross-sectional stress of composite girders will mainly withstand by the reinforcing bars and the steel girder, and the composite neutral axis begin to keep as constant at around the plastic neutral axis.

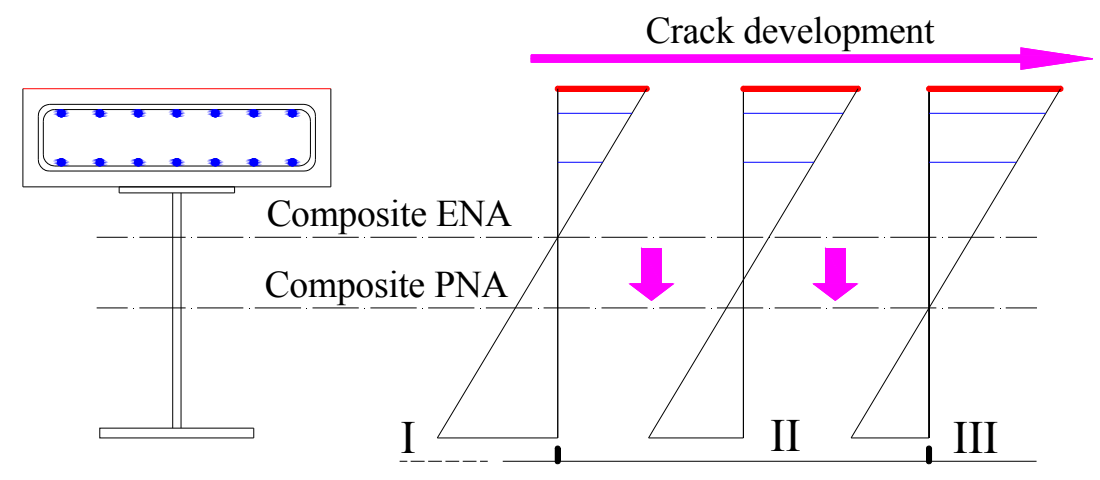

Figure 11. Movement of Neutral Axis 

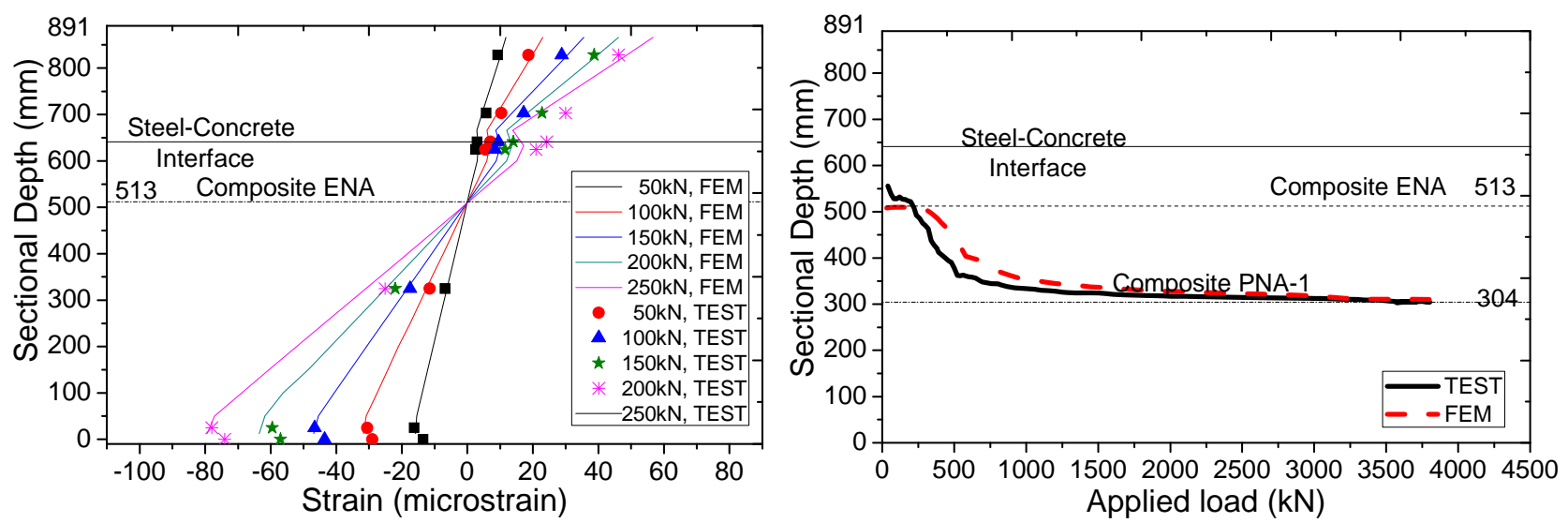

Figure 12. Strain Distribution and Neutral Axis Movement of CBS
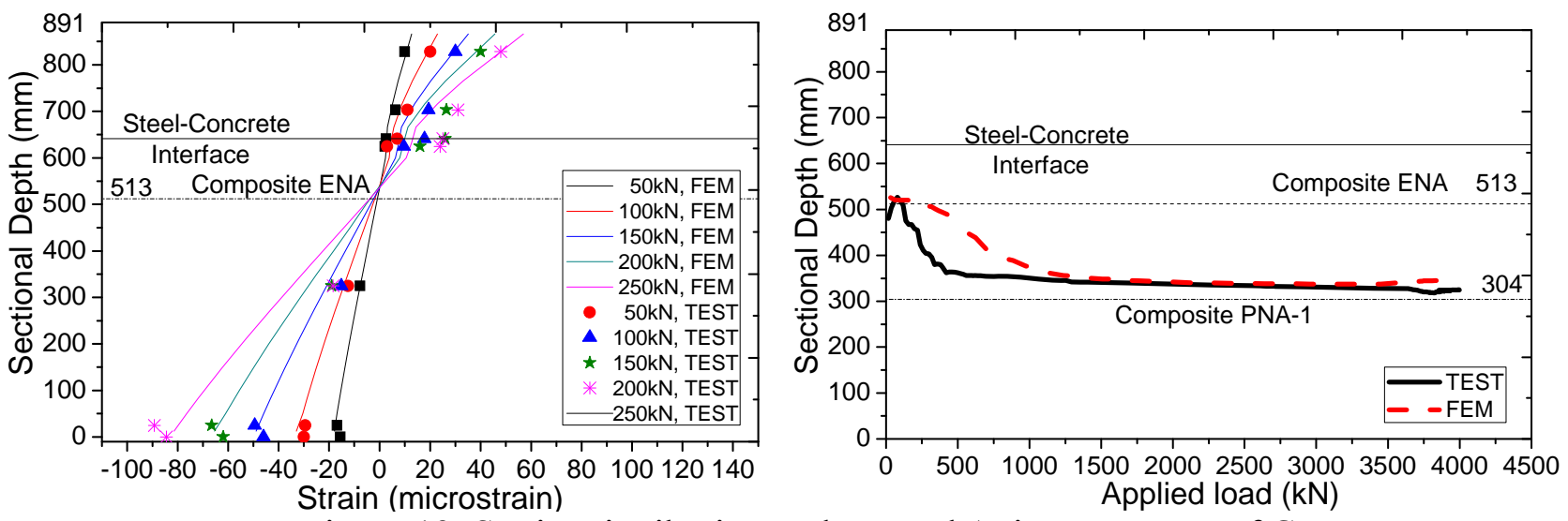

Figure 13. Strain Distribution and Neutral Axis Movement of CBP

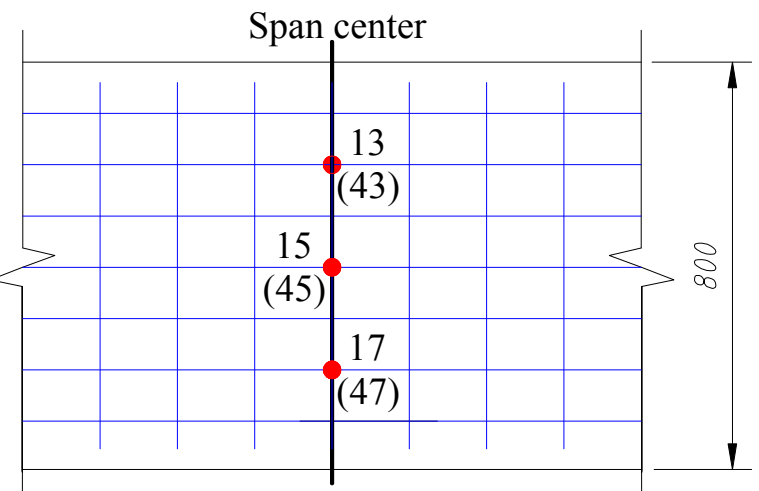

Figure 14. Position of Reinforcement Strain Gauges

\subsection{Strain of Reinforcements}

The strains of longitudinal reinforcements in the mid-span near the loading point were measured in the tests, and the results of CBS and CBP were presented herein. Figure 14 shows gauges' number (gauges 13, 15, 17 were arranged for the upper layer reinforcements, and gauge 43, 45, 47 were employed for the lower layer reinforcements) as well as their positions, and the load-strain relationships were depicted in Figures 14 and 15. Strain development of the reinforcement before theoretical girder yielding load as well as the strain results during the whole loading process were illustrated separately. Numerical strain results of reinforcements were also given. During the whole loading process, no obvious difference of numerical strain results was found between different reinforcements in the same layer. Average values for both upper and lower layers were given separately to compare with the test results. 
The strain increased linearly and slowly before the concrete slab cracking. After the initial cracking, the strain near the point where the crack has occurred increased rapidly (often referred to as strain jump). Similar phenomenon was also confirmed in the numerical studies, shown in Figure 15(a) and Figure 16(a). In regard to the initial cracking moment, results in Table 4 indicate that the numerical results agree well with the theoretical values, but larger than the test values. It demonstrates that for steel-concrete composite structures subjected to hogging moment, the concrete slab will crack and thus making the structural behavior highly nonlinear even for low stress levels.

Until the theoretical girder yielding load of the specimen, the reinforcements were continuously deformed and the strain of upper layer reinforcements was found larger than those of lower reinforcement. Comparison between numerical and theoretical results indicates that numerical strain results of reinforcements had a similar variation trend but a little bit smaller than test values, which might be caused by the initial cracks in the concrete slab that cannot be considered in the numerical simulation. Beside, as the concrete in tension zone are usually suggested to be ignored for girder yielding and ultimate strength calculation, resulting in theoretical yielding loads were smaller than the test values, as shown in Figure 15(b) and Figure 16(b). Thus, the tension stiffening effect between cracks should be considered in order to evaluate the more exact flexural stiffness of the composite section under hogging moments.

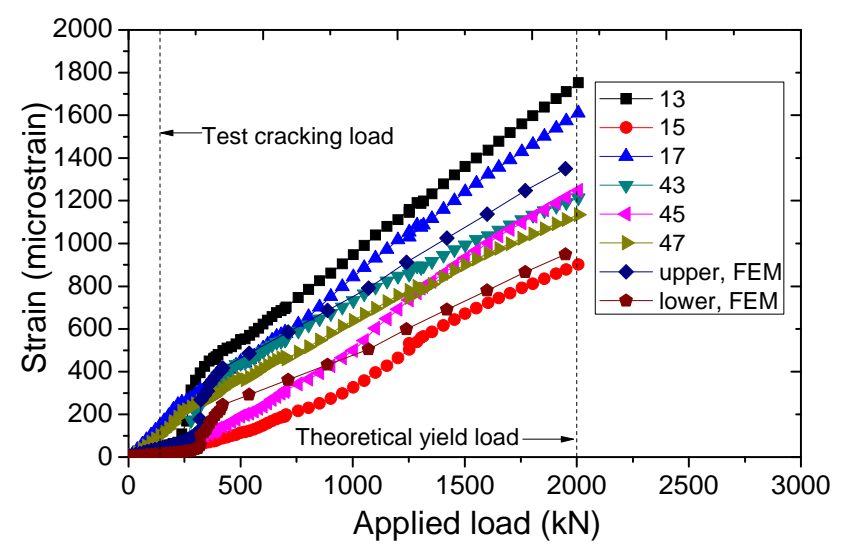

(a) $\mathrm{P}<2000 \mathrm{kN}$

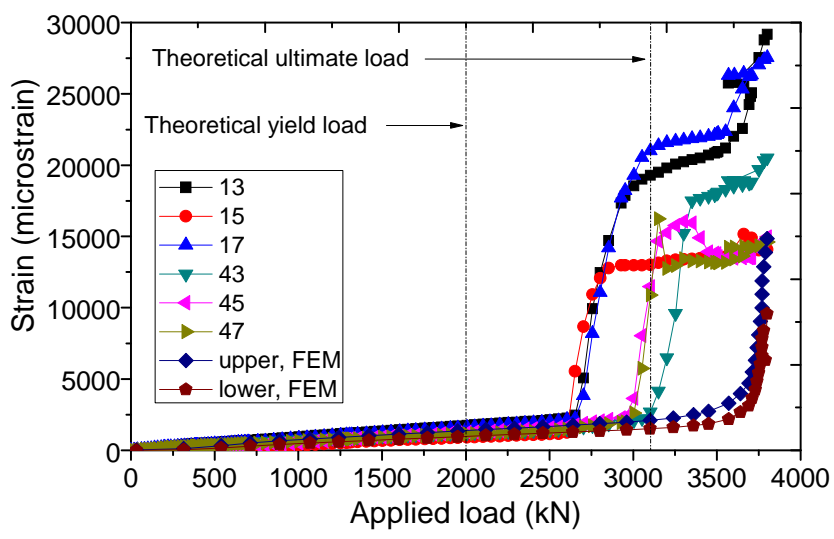

(b) Whole Loading Process

Figure 15. Strain Development of Reinforcing Bars of CBS 


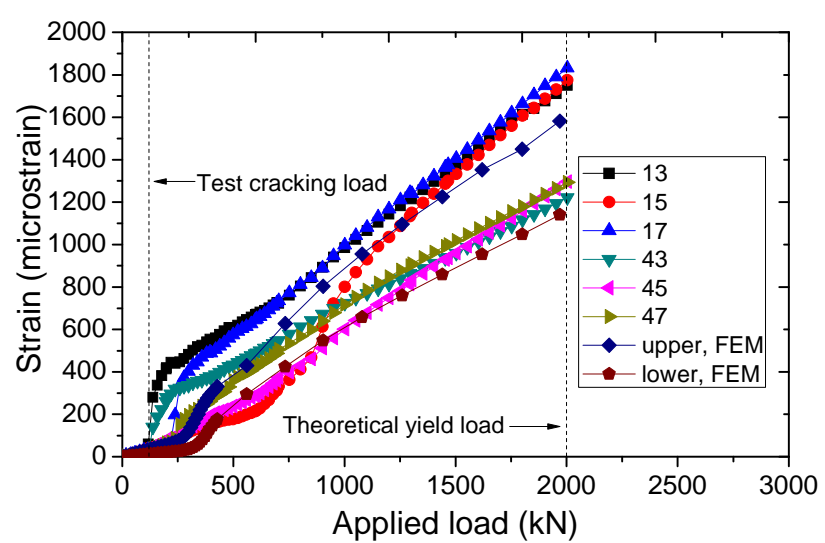

(a) $\mathrm{P}<2000 \mathrm{kN}$

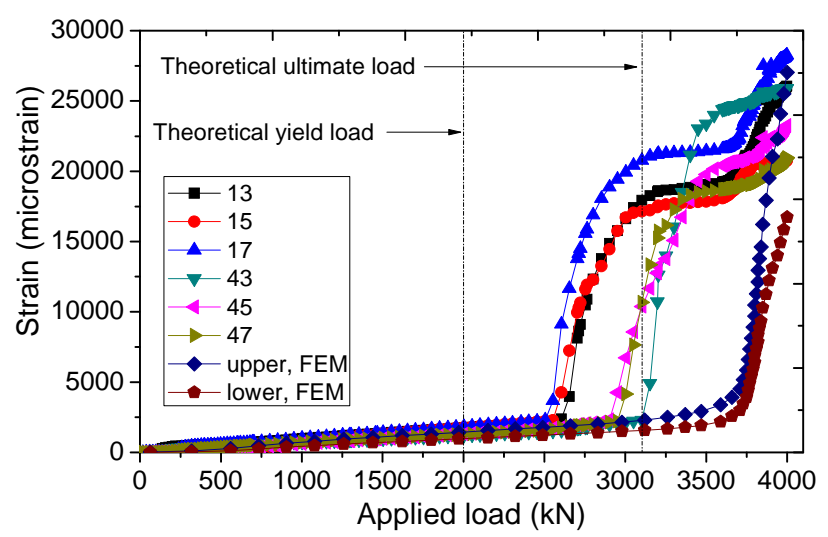

(b) Whole Loading Process

Figure 16. Strain Development of Reinforcing Bars of CBP

Furthermore, as perfect bond was assumed for interface between reinforcing bars and surrounding concrete, resulting in smaller strain during the loading process and deferred Re-bar yielding in the numerical analysis. Also, strain hardening of the reinforcements was confirmed in the experiment for some reinforcements. However, for some other reinforcements, the strain was declined before strain hardening was obtained, which could be caused by the bond effect failure between the concrete and the reinforcement. Therefore, strain hardening effect of reinforcement for composite girders in negative bending moment region seems can be ignored.

\subsection{Crack Formation and Development on Concrete Slab}

Initial crack formation, crack width development during the loading process and distribution on the concrete slab were recorded by using $14 \pi$-gauges on the top surface of the concrete slab. Numbers, locations as well as arrangement of $\pi$-gauges in the experiments were shown in Figure 17. CBS was taken as an example. As mentioned earlier, loading, unloading and reloading process were applied in this experiment, thus, recorded results during the loading process of $0-400 \mathrm{kN}$, and final reloading process until the ultimate load were presented in Figure 18 in order to show the initial cracking behavior of concrete and crack development of composite beam during the whole loading process. Detailed experimental results of initial cracking and cracking width development were illustrated in Figures 18 (a) and (c). Besides, crack width calculated by considering the maximum crack spacing (taken as $217 \mathrm{~mm}$ according to JSCE specification [15]) and rebar strains from numerical models was illustrated as numerical results, shown in Figures18 (b) and (d), in which the average experimental values of crack width were given to make a comparison. 
The crack width jump shown in Figure 18(a) indicates that the initial cracks occurred at the top of concrete slab near loading position when applied load reached to $220 \mathrm{kN}$, which is a little bit smaller than the numerical and theoretical results, as shown in Figure 18(b). The comparison indicates that the proposed numerical model can simulate the un-cracked section well and give similar results to experimental values, although there is a small difference between experimental and numerical responses just after initial cracking.

Figure 18(c) shows the crack width development during the whole loading process. With increasing of the load, the cracks propagated and distributed. At a crack, the rebar strain is maximum and the concrete strain is zero. In between cracks, the rebar strain is minimum and the concrete strain is maximum. If, under increasing load, the concrete strain reaches the limiting tensile strain, an intermediate crack forms between two previously formed cracks. When new crack occurs, "crack jump" for existing cracks was confirmed in the experiments. The results shown in Figure 18(d) demonstrate that before rebar yielding, the assumption of perfect bond between rebar and surrounding concrete will not affect the crack width and the numerical simulation has similar results in comparison with test values. Also, the results indicate that the smeared crack model that usually used in commercial software is capable for simulating the crack development process. However after Re-bar yielding, non-ignorable slip is produced between rebar and concrete, resulting in larger difference between numerical and experimental results.

In addition, a very interesting phenomenon of "crack closure" was observed in the test for both CBS and CBP, and the crack width was found suddenly to become small and keep as constant for all large cracks before the ultimate load was reached, shown as Figure 18(d). This might be because the sectional through cracks were generated, and the bond on the steel-slab interface and the rebar-surrounding concrete interface was broken. For the concrete between through cracks, no tension transfer mechanism between through cracks causes the reduction of the crack width, which is experimentally observed as "crack closure" in the test. Due to the strain hardening of the steel girder and some reinforcing bars, the section could continue to sustain more loads after the "crack closure" was observed. However, as the concrete was out of service, the girder stress as well as its deformation increased rapidly until the ultimate load was reached. Nevertheless, similar phenomenon cannot be obtained in the numerical analysis due to perfect bond assumption between concrete and reinforcing bars. A similar load-crack width response during the whole loading process was also confirmed in results of CBP specimen, as shown in Figure 19.

Results of PBL specimen were illustrated in Figure 19, which have the similar behavior with stud specimen. But it should be noted that both numerical and experimental initial cracking and girder yielding loads of CBP is smaller than those of CBS. Furthermore, as this experimental behavior of "crack closure" is similar to the assumptions for the calculation of ultimate load in current specifications such as AASHTO[31], JSCE[15], Eurocode-4[33] and GB-2003[34], thus "crack closure" load of each test specimen was presented and made a comparison with theoretically and experimental ultimate load, as listed in Table 5. The results indicate that the "crack closure" loads are always slightly larger than the code specified (theoretical) ultimate strength but smaller than the experimentally ultimate loads, which seems to indicate that the current codes for ultimate loading capacity of composite girder under negative bending moment is suitable for practical design because "crack closure" always happen after the theoretically ultimate loading capacity was reached. 


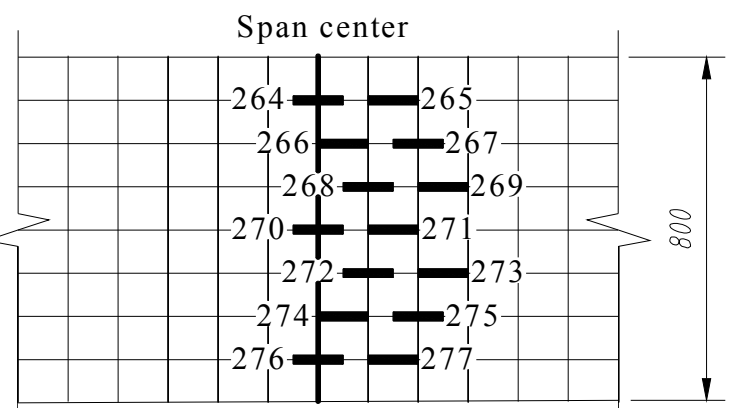

(a) П-Gauge Locations and Gauge Numbers

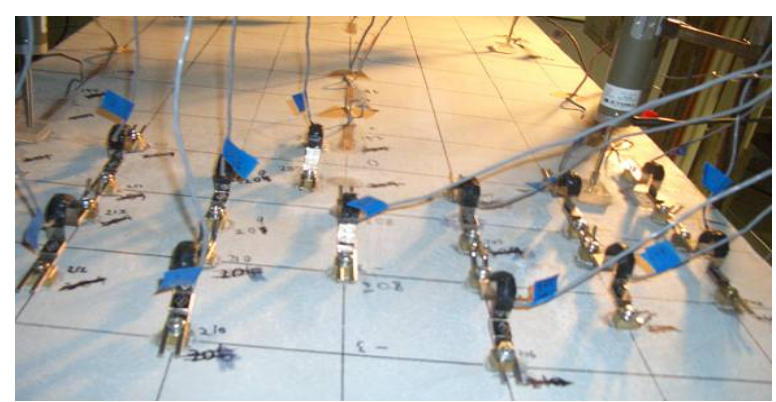

(b) П-Gauge Arrangement in the Test

Figure 17. Locations and Arrangement of П-Gauges (100mm square meshes on the surface of the concrete slab)

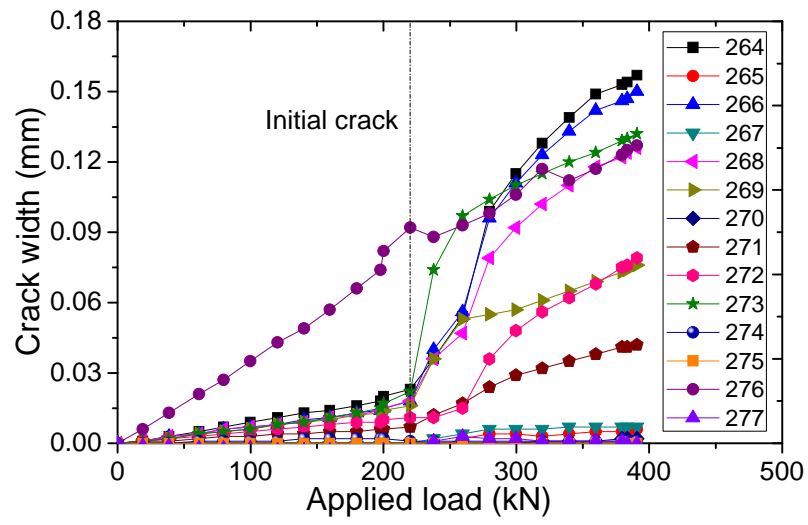

(a) Reloading Process from 0 to $400 \mathrm{kN}$

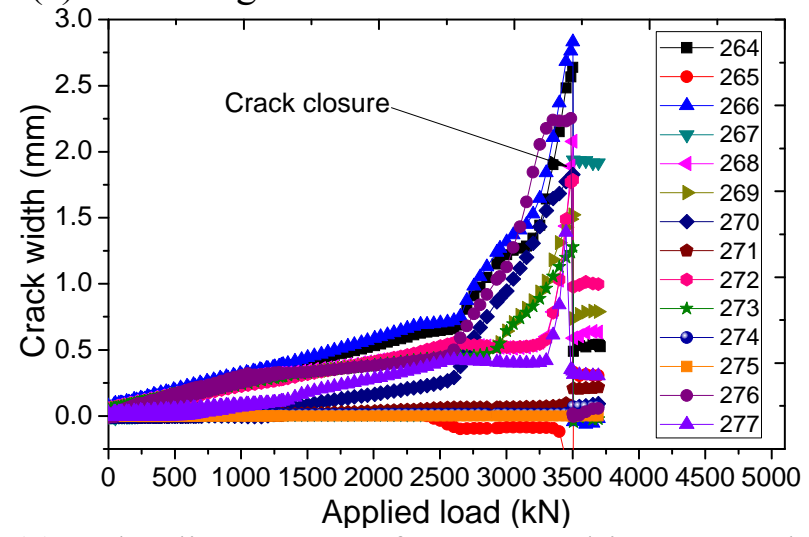

(c) Reloading Process from 0 to Ultimate Load

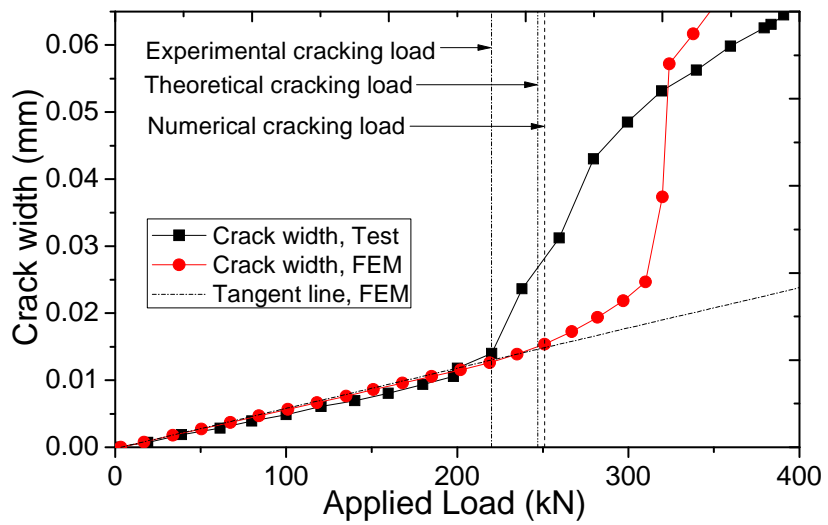

(b) Numerical and Experimental Initial Cracking

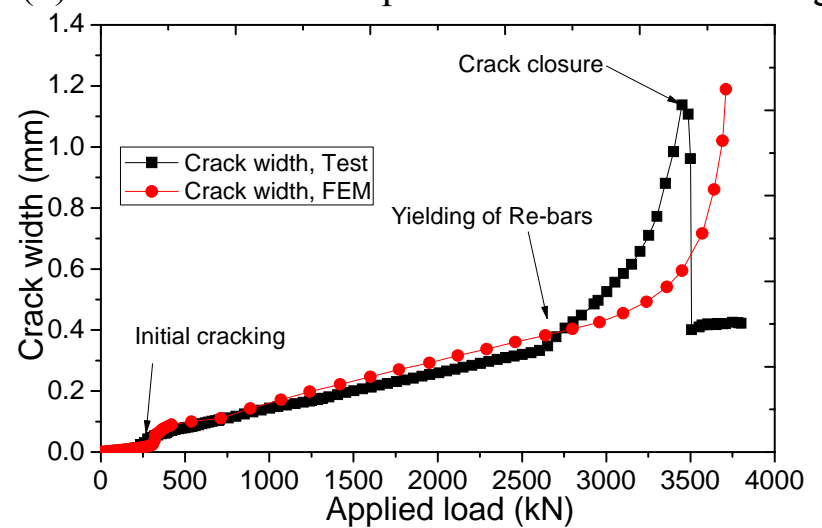

(d) Numerical and Experimental Crack Width

Figure 18. Crack Width Development Process of CBS 


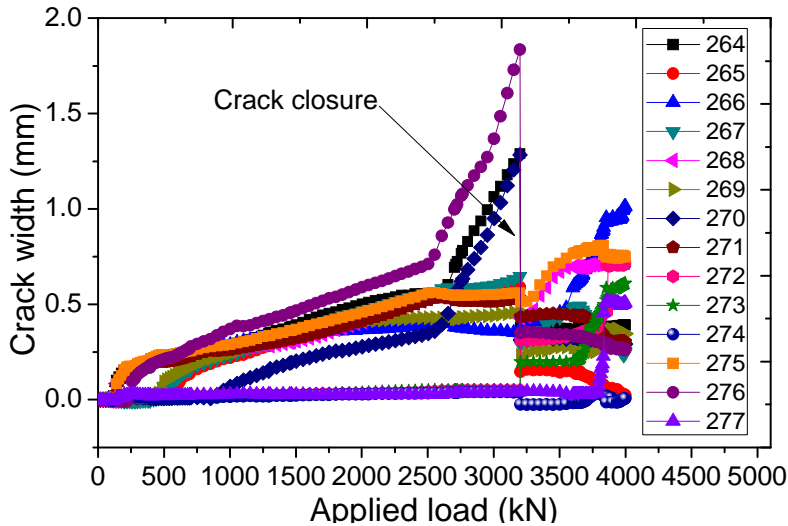

(a) Reloading Process from 0 to Ultimate Load

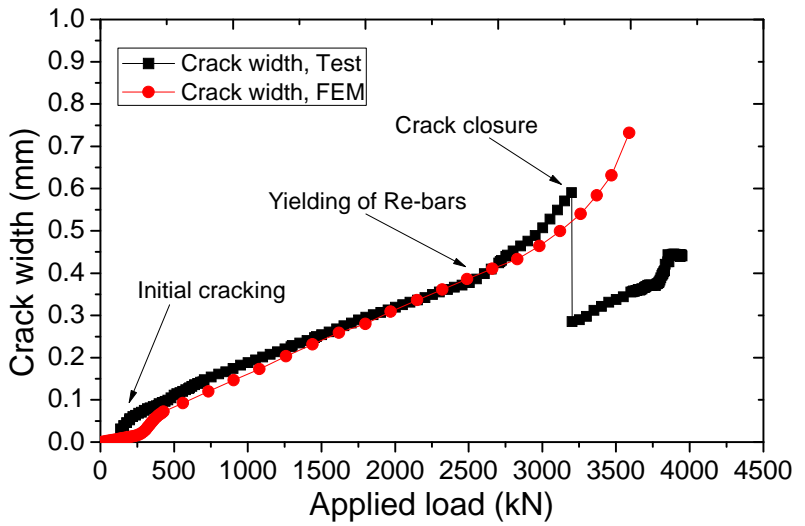

(b) Numerical and Experimental Crack Width Figure 19. Crack Width Development Process of CBP

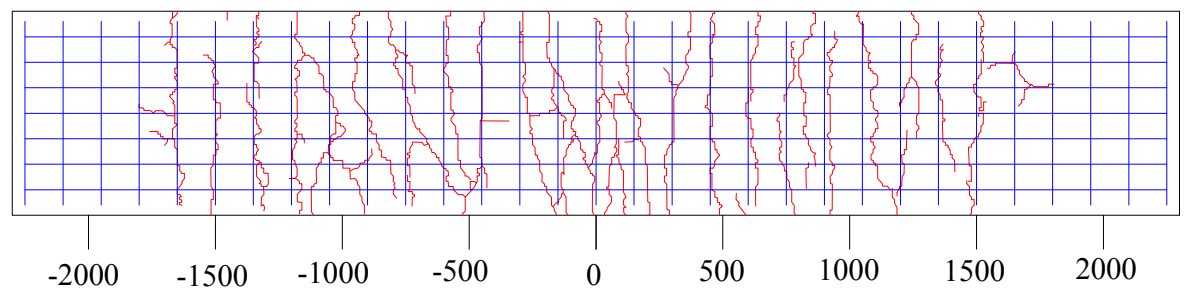

(a) Crack Distribution of CBS

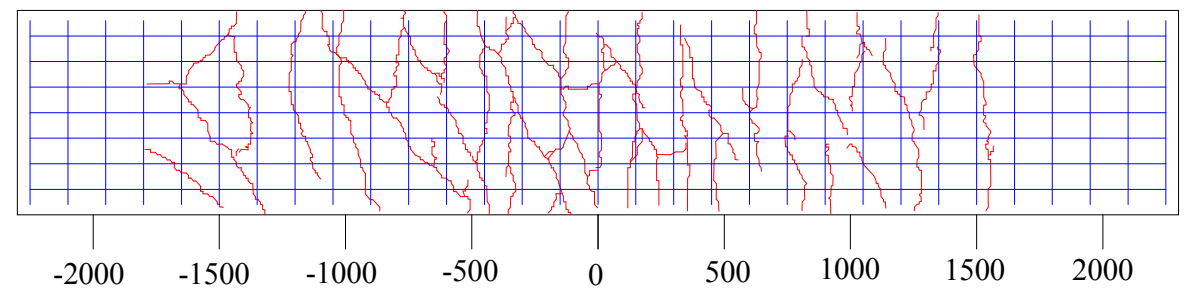

(b) Crack Distribution of CBP

Figure 20. Crack Distribution on the Surface of Concrete Slab After Loading Test (Note: The horizontal coordinate represents the distance from the loading point, the grid in blue stands for the place of reinforcement, and the line colored in red shows the cracks.)

Table 6. Crack Spacing of Test Specimens

\begin{tabular}{|c|c|c|c|c|c|}
\hline \multicolumn{2}{|c|}{ Test crack spacing (mm) } & \multicolumn{2}{|c|}{ CEB-FIP crack spacing (mm) [35] } & \multicolumn{2}{c|}{ JSCE maximum crack spacing $L_{\max }(\mathrm{mm})$} \\
\hline Maximum & Average & Maximum & Average & JSCE(2007) [15] & MLIT(2009) [36] \\
\hline 200 & 150 & 265.9 & 177.3 & 217 & 204 \\
\hline
\end{tabular}

Figure 20 shows the crack distribution on the concrete slab surface of each specimen after the loading test. It was observed that in the ultimate stage, the cracks mainly distributed in a direction perpendicular to the girder axis, which means the cracks were mainly dominated by bending moment. With the entire specimens, crack spacing ranges from 100 to $200 \mathrm{~mm}$, with an average value of $150 \mathrm{~mm}$, coinciding with the spacing between the reinforcement stirrups. Also, it was found that the maximum experimental crack spacing is almost twice the minimum, which is consistent with the theoretical findings [37]. Furthermore, no obvious difference about crack distribution was observed between Studs and PBLs specimens.

The test crack spacing was also compared with the maximum crack spacing specified by CEB-FIP and JSCE, as summarized in Table.6. The comparison indicates that code specified cracking spacing is relatively close to the test values and can be regarded as appropriate values. The comparison shown in Figures 18(d) and 19(d) also demonstrate that the code-based crack spacing results are appropriate values in predicting the cracking width on the concrete slab. 


\subsection{Effects of Rubber-Latex Mortar Coating}

As the key point in this research, effects of rubber-latex mortar on mechanical behavior of steel-concrete composite girders subjected to hogging moment were studied from the following three aspects: impact test of the steel girder (about the noise reduction), interface slip on key sections and flexural strain of the shear studs.

\subsubsection{Impact test}

Impact test was performed for steel girder before and after rubber-latex mortar coating. Previous researches show that the steel girder noise was mainly produced from the steel web [38], so that accelerometers were arranged on the middle center of the web in the 1/4 span. Impact force by using harmer was applied in the bottom plate in the span-center section. The test set-up was shown in Figure 21. Also, as for steel girders the structure borne noise was remarkable when the frequencies from 125 to $2000 \mathrm{~Hz}$, sound pressure levels within this range was recorded, and the all pass value (AP) was also calculated within this range.

The 1/3 octave filters results shown in Figure 22 indicates that the sound pressure level of $5-15 \mathrm{~dB}$ was reduced after rubber-latex mortar painting, and about $10 \mathrm{~dB}$ sound level reduction can also be confirmed for AP values. With the application of rubber-latex mortar coating, damping performance of the structural members will be enhanced, and the mass of the structures will be increased, which might be the reasons for noise reduction of the test specimens.
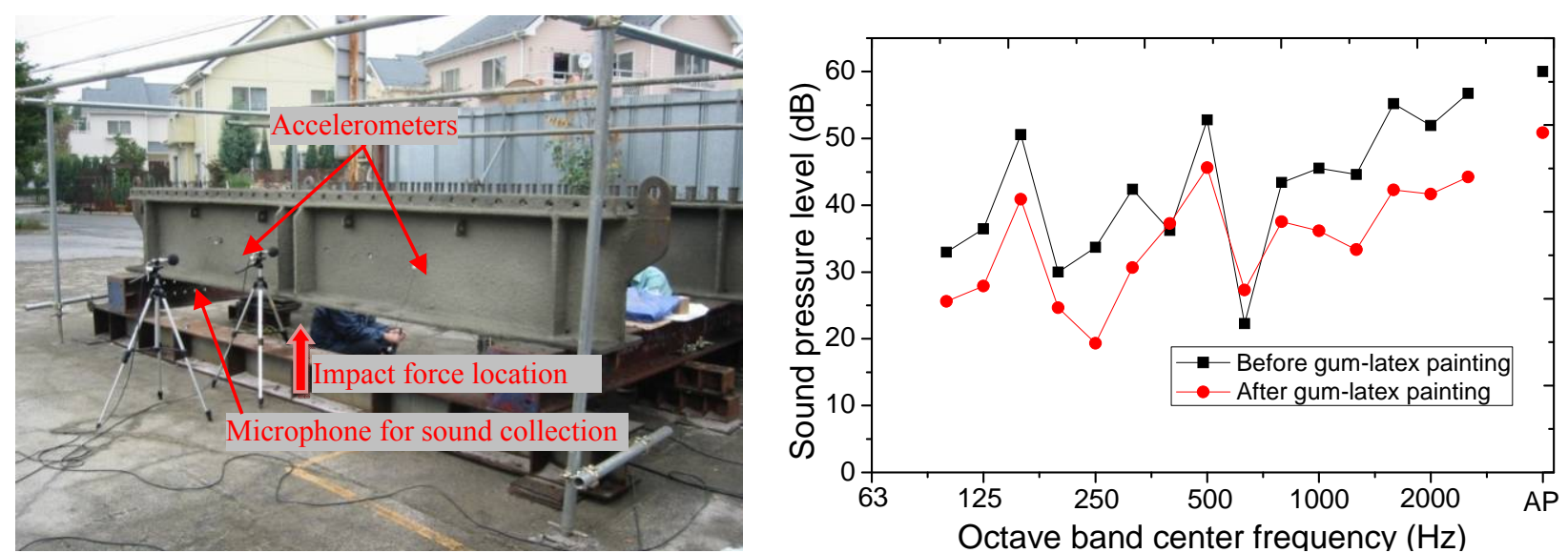

Figure 21. Set-Up of the Impact Test

Figure 22. Impact Noise Before and After Rubber-Latex Coating

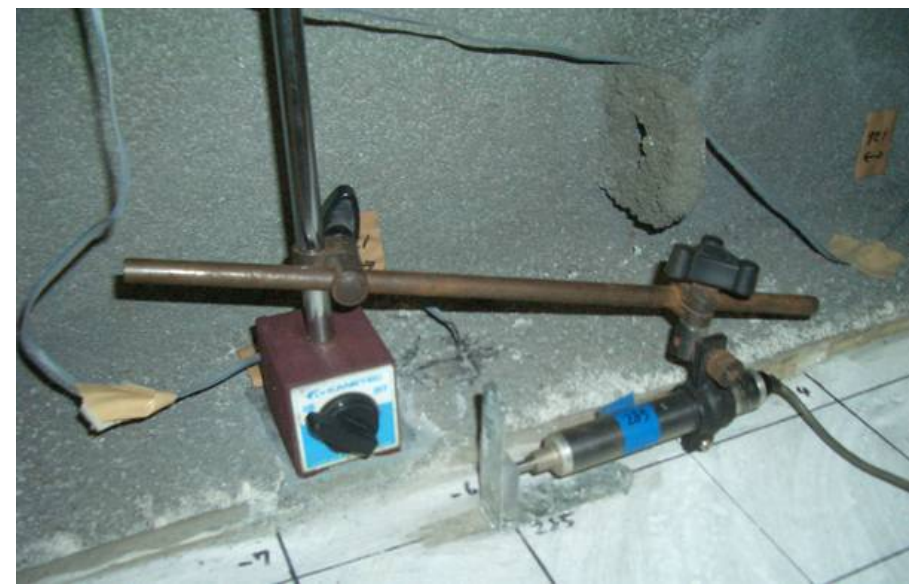

Figure 23. Arrangement of the Linear Variable Differential Transducers (LVDTs) 


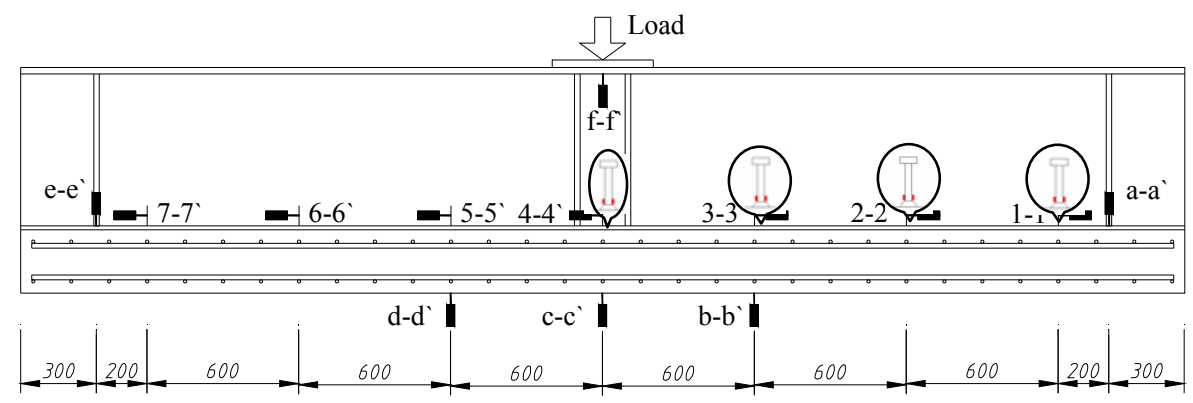

Figure 24. Arrangement of Linear Variable Differential Transducers (LVDTs)

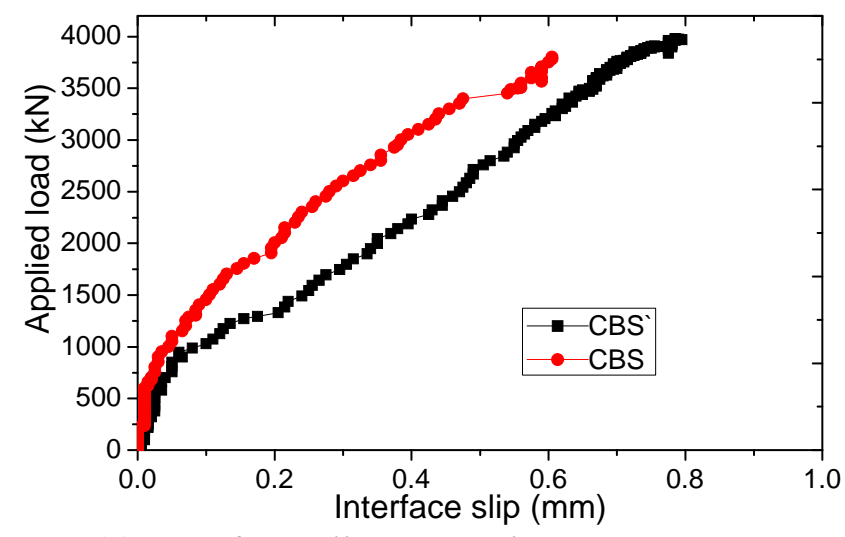

(a) Interface Slip on Section 1-1

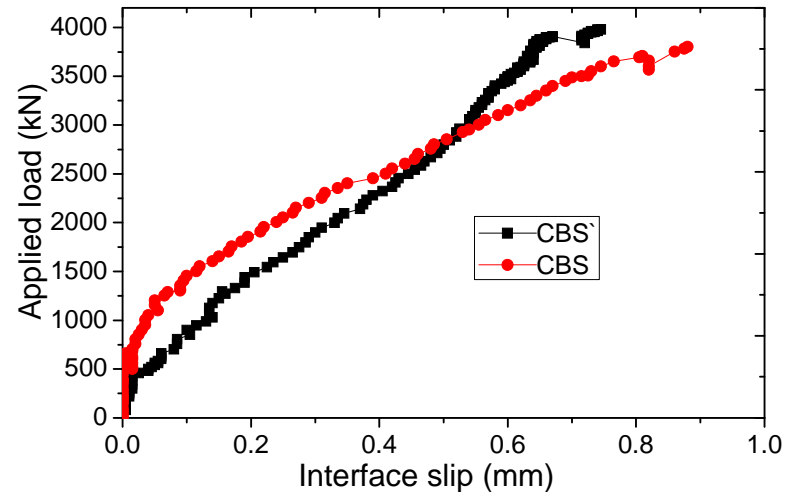

(c) Interface Slip on Section 3-3`

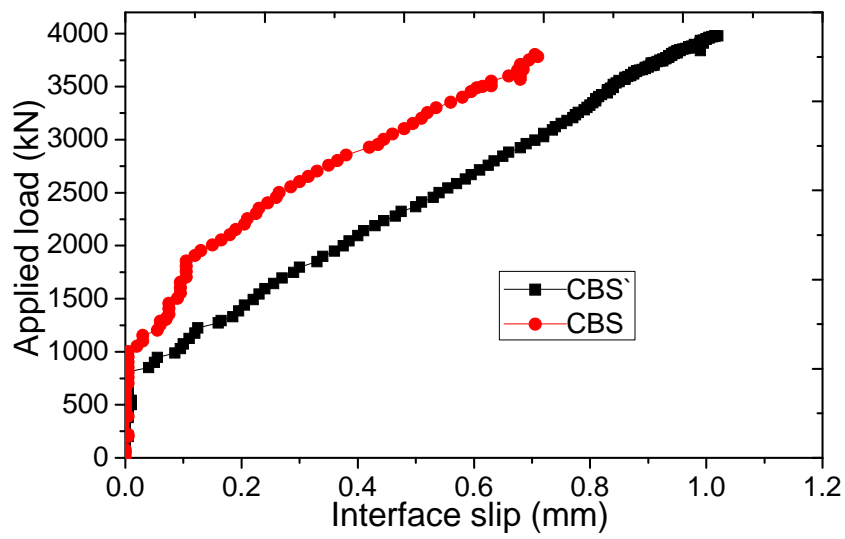

(b) Interface Slip on Section 2-2`

Figure 25. Comparison of Slip Developing Process between CBS and CBS`

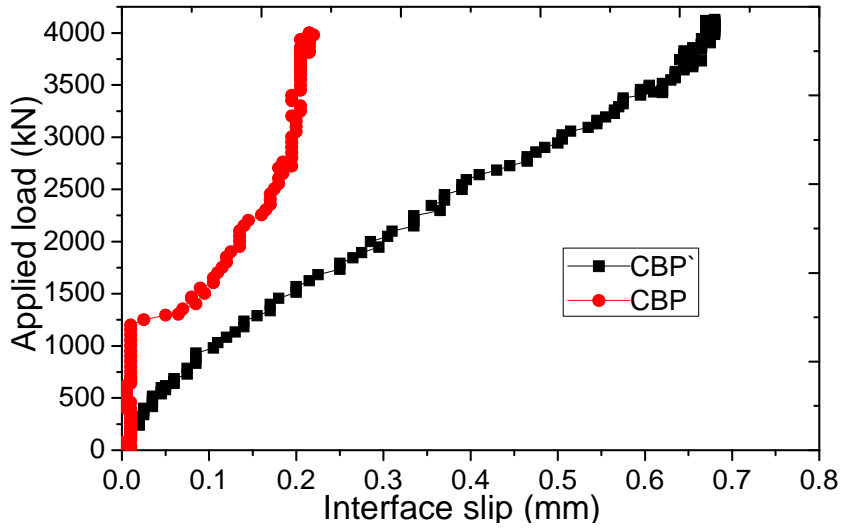

(a) Interface Slip on Section 1-1

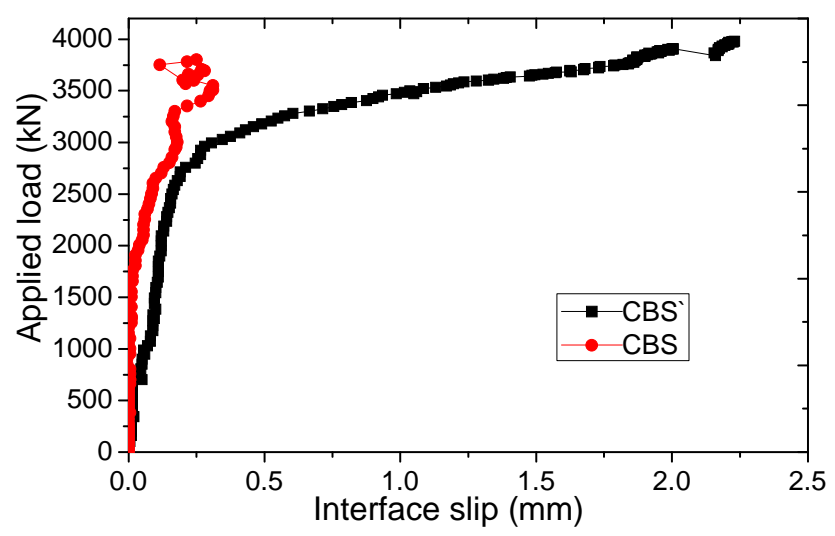

(d) Interface Slip on Section 4-4

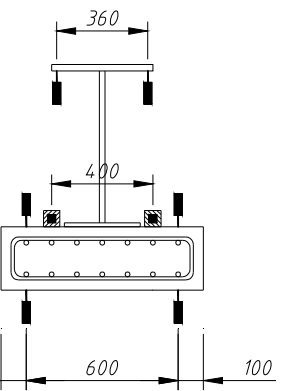




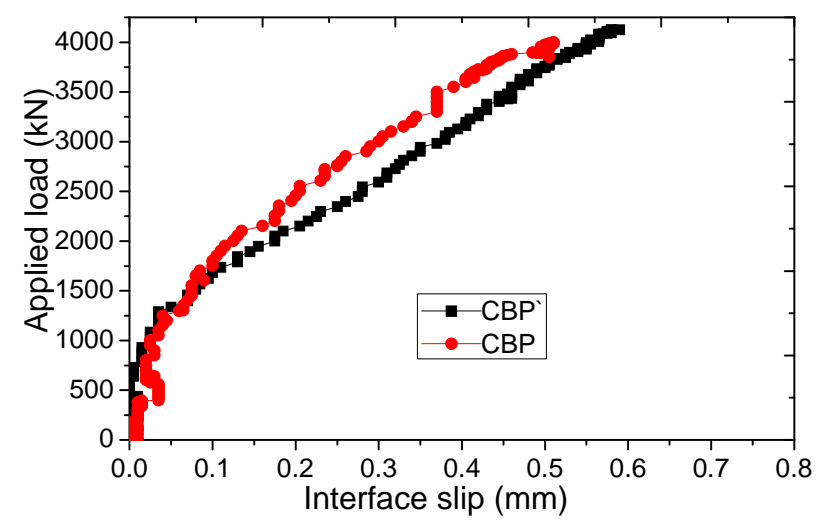

(c) Interface Slip on Section 3-3

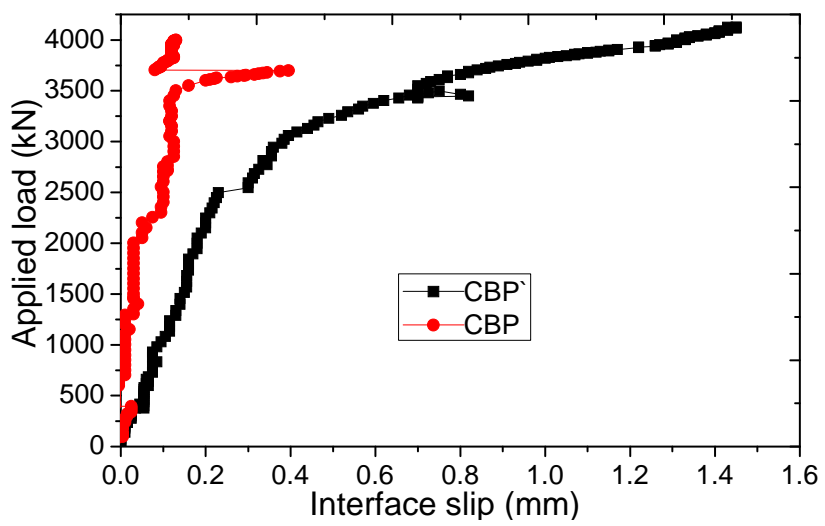

(d) Interface Slip on Section 4-4

Figure 26. Comparison of Slip Developing Process between CBP and CBP`

\subsubsection{Interface slip}

In order to learn the influence of rubber-latex mortar coating, slip development on key sections was observed and recorded in the test and compared with previous experimental results [32, 39]. CBS ' and CBP', which have same size dimension and similar material with CBS and CBP, were not sprayed with rubber-latex mortar. Interface slip was measured on seven different sections along the longitudinal direction by mean of linear variable differential transducers (LVDTs), as shown in Figures.23 and 24 .

The interface slip at the different sections of 1-1', 2-2', 3-3`, 4-4' of these four test specimens was generated respectively and compared as shown in Figures 25 and 26. The results indicate that the slip increases with the load increase and the interface slip is relatively small when both the studs and PBLs beyond their yield load. Comparison indicates that the girders CBS and CBP have much smaller interface slip, which demonstrates that the rubber-latex mortar coating has a significant effect on reducing the interface slip, thus the adhesion bonding effects of rubber-latex mortar coating was confirmed. Besides, slip results comparison between CBS and CBP also illustrate that PBL connectors have relatively smaller slip in comparison with that of stud connectors.

\subsubsection{Flexural strain results of shear studs}

Moreover, shear studs were also painted with rubber-latex mortar, and two strain gauges were arranged in the vertical direction at the root of each stud in sections of 1-1', 2-2', 3-3', 4-4' (shown in Figures 24, 27 and 28). Flexural strain was taken as the average of the tension and compression strains. Previous test results of CBS (similar design of CBS without rubber-latex mortar) were given and compared with results of CBS.

The flexural strain of studs in sections of 2-2`, 3-3`, 4-4 during the loading process was compared between CBS and CBS' in Figure 29 (the gauges were failed on sections 1-1' of CBS during the test), it was found that the strain increased approximately bi-linear as the load increased, while the increase of slope after cracking was larger than that before cracking. Under the ultimate state, however, the values of strain for shear connectors were less than the yield strain. Therefore, the connection between the steel girder and concrete slab was reliable until the ultimate state. Besides, the comparison also indicates that the flexural strain of the stud in CBS was much smaller than that of CBS', and the flexural stiffness of studs with rubber-latex mortar seems to increase by using rubber-latex mortar. 


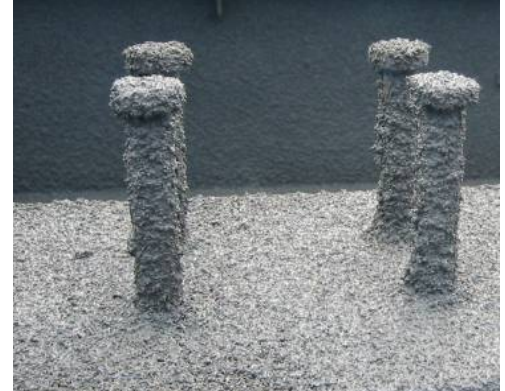

Figure 27. Rubber-Latex Mortar on Studs

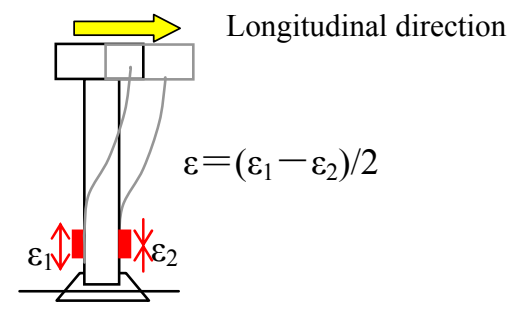

Figure 28. Arrangement of Strain Gauges on Stud

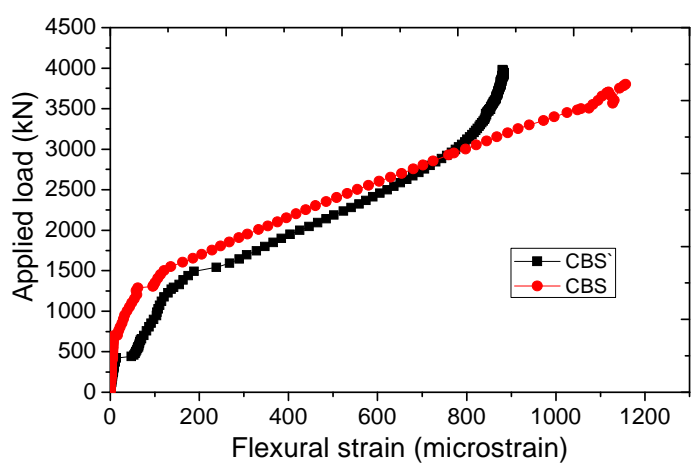

(a) Section 2-2

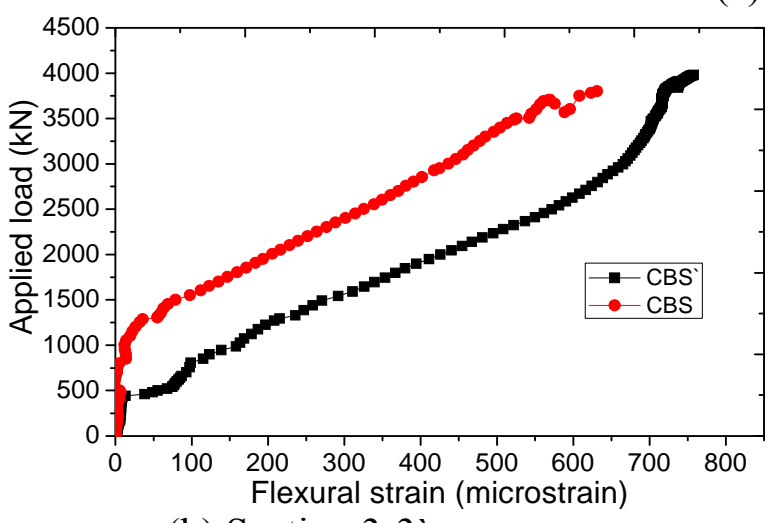

(b) Section 3-3

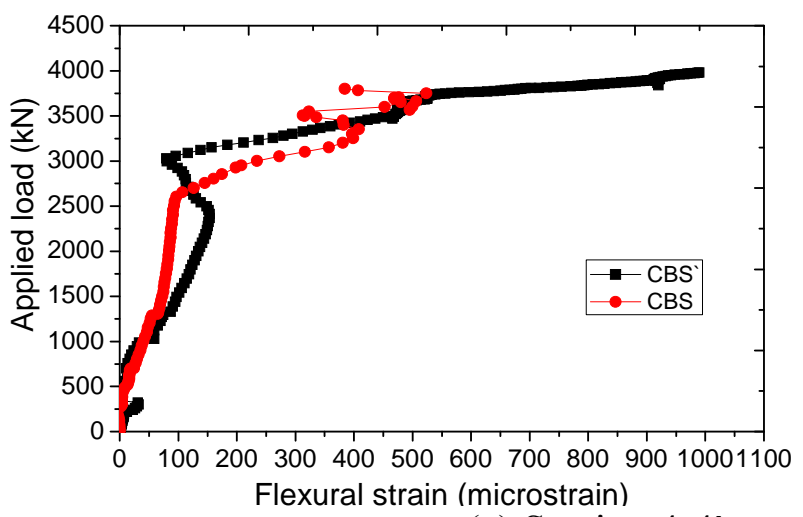

(c) Section 4-4

Figure 29. Comparison of Flexural Strain between Studs with (CBS) and without (CBS`) Rubber-Latex Mortar

\section{CONCLUDING REMARKS}

The experimental and numerical studies were performed to investigate the inelastic behavior of steel-concrete composite girder subjected to hogging moment. The load-displacement relations, strain distribution and movement of the sectional neutral axis as well as the crack and interface slip developing process were presented in this paper. Experiments based 3-D nonlinear finite element models were also established. From the present results, the following conclusions and recommendations deserving priority are made:

(1) Proposed numerical models can simulate the test specimens well on the basis of the present load-deformation response, sectional strain distribution, rebar yielding and crack developing process on the concrete slab, thus it follows that proposed numerical method can be served as a basis for the design of steel-concrete composite girders under hogging moment. Besides, perfect bond assumption for concrete-reinforcement interface was proved suitable before rebar yielding, but relatively large difference was produced after rebar yielding. 
(2) Results from the impact test indicate that the application of rubber-latex mortar can be beneficial to reducing the noise pressure levels (about $10 \mathrm{~dB}$ in the present test). Flexural stiffness of the shear connectors was also found to be enhanced by using rubber-latex mortar. Besides, adhesion bonding effects of rubber-latex mortar on the interface were confirmed in the tests by comparing with specimens without using rubber-latex mortar.

(3) Both PBLs and Stud connectors are effective shear connective devices for composite girders subjected to negative bending moment, and no obvious differences were found except that PBL connectors could slightly improve the rigidity of the composite girder under both the serviceability limit state and the ultimate limit state in comparison with stud connectors according to the experimental load-displacement relationship as well as the interface slip. Stud specimens have relatively better mechanical behavior in regard to concrete cracking, such as initial cracking and crack closure.

(4) It is considered that the composite neutral axis moves between the cross-sectional elastic neutral axis and the plastic neutral axis. The location of the composite neutral axis was found to be the same as un-cracked section before cracking. After cracking, tension stiffening of the concrete between cracks is suggested to be considered when determining the location of the neutral axis.

(5) Average crack spacing on concrete slab was found mainly dependent on the transverse reinforcement, and the maximum crack spacing specified by current specifications was proved to be appropriate in comparison with test values. Furthermore, code-based ultimate loads were similar to test results, and current specifications based on the plastic analysis were proved to be appropriate as a design method on the safe side.

\section{ACKNOWLEDGMENTS}

The experimental work was carried out in the Structural Laboratory of Waseda University, Tokyo, Japan. The financial support sponsored by Ministry of Land, Infrastructure, Transport and Tourism of Japan is gratefully acknowledged. Special thanks were given to Assoc. Prof. Taniguchi from Maebashi Institute of Technology in Japan (Formerly, senior researcher at Railway Technical Research Institute) for his suggestions and test supports to this study.

\section{REFERENCES}

[1] Manfredi, G., Fabbrocino, G. and Cosenza, E., "Modeling of Steel-concrete Composite Beams under Negative Bending", Journal of Engineering Mechanics, ASCE, 1996, Vol. 125, No. 6, pp. 654-662.

[2] Ryu, H.K, Chang, S.P., Kim, Y.J. and Kim, B.S., "Crack Control of a Steel and Concrete Composite Plate Girder with Prefabricated Slabs under Hogging Moments", Engineering Structures, 2005, Vol. 27, No. 11, pp. 1613-1624.

[3] Ryu, H.K., Kim, Y.J. and Chang, S.P., "Crack Control of a Continuous Composite Two-girder Bridge with Prefabricated Slabs under Static and Fatigue Loads", Engineering Structures, 2007, Vol. 29, No. 6, pp. 851-864.

[4] He, J., Liu, Y., Chen, A. and Yoda, T., "Experimental Study on Inelastic Mechanical Behaviour of Composite Girders under Hogging Moment”, Journal of Constructional Steel Research, 2010, Vol. 66, No. 1, pp. 37-52.

[5] Chen, S. and Jia, Y., "Required and Available Moment Redistribution of Continuous Steel-concrete Composite Beams", Journal of Constructional Steel Research, 2008, Vol. 64, No. 2, pp. 167-175. 
[6] Chen, S., Jia, Y. and Wang, X., "Experimental Study of Moment Redistribution and Load Carrying Capacity of Externally Prestressed Continuous Composite Beams", Structural Engineering and Mechanics, 2009, Vol. 31, No. 5, pp. 605-619.

[7] Fan, J., Nie, J., Li, Q. and Wang, H., "Long-Term Behavior of Composite Beams under Positive and Negative Bending. I : Experimental Study", Journal of Structural Engineering, ASCE, 2010, Vol. 136, No. 7, pp. 849-857.

[8] Fabbrocino, G., Manfredi, G., and Cosenza, E., "Analysis of Continuous Composite Beams including Partial Interaction and Bond", Journal of Structural Engineering, ASCE, 2000, Vol. 126, No. 11, pp. 1288-1294.

[9] Nie, J., Fan, J. and Cai, S., "Stiffness and Deflection of Steel-Concrete Composite Beams under Negative Bending", Journal of Structural Engineering, ASCE, 2004, Vol. 130, No. 11, pp.1842-1851.

[10] Loh, H.Y., Uy, B. and Bradford, M.A., "The Effects of Partial Shear Connection in the Hogging Moment Regions of Composite Beams Part II-Analytical Study”, Journal of Constructional Steel Research, 2004, Vol. 60, No. 6, pp. 921-962.

[11] Nguyen, Q.H., Hjiaj, M., Uy, B. and Guezouli, S., "Analysis of Composite Beams in the Hogging Moment Regions using a Mixed Finite Element Formulation", Journal of Constructional Steel Research, 2009, Vol. 65, No. 3, pp. 737-748.

[12] Lin, W. and Yoda, T., "Inelastic Behavior of Continuous Steel-Concrete Composite Beams with Gum-Latex Mortar Coating”, Proceedings of the 2011 World Congress on Advances in Structural Engineering and Mechanics (ASEM+), 2011, pp. 5451-5459.

[13] Lin, W., Yoda, T., Taniguchi, T. and Hansaka, M. "Performance of Strengthened Hybrid Structures Renovated from Old Railway Steel Bridges." Journal of Constructional Steel Research, 2013, Vol. 85, pp. 130-139.

[14] Taniguchi, N., Hansaka, M., Koide, N., Ogaki, K., Okubo, F. and Saeki, T., "Study of the Hybrid Structures changed from the Steel Bridges for Railroad which Considered Construction", Journal of Structural Engineering, JSCE, 2011, Vol. 57A, pp. 1052-1059. [in Japanese].

[15] Japan Society of Civil Engineers, "Standard Specifications for Steel and Composite Structures 2007”, 2007, pp.250-259.

[16] Taniguchi, N. and Ikeda, M., "Experimental Study on a Crack Formation for Railway Composite Girders with Negative Bending", Proceedings of the Third International Conference on Steel and Composite Structures ICSCS07, Manchester, UK, 2007, pp. 915-920.

[17] Hognestad, E., "A Study of Combined Bending and Axial Load in Reinforced Concrete Members", University of Illinois Engineering Experiment Station, Bulletin Series, 1951, No. 399, pp. 40-54.

[18] Park, R. and Paulay, T., "Reinforced Concrete Structures", John Wiley and Sons, Inc., 1975, pp.11-36.

[19] Nakasu, M. and Iwatate, J., "Fatigue Experiment on Bond between Concrete and Reinforcement", Transaction of JSCE, 1996, Vol. 426, pp. 852-853.

[20] Wang, Y. C., "Deflection of Steel-concrete Composite Beams with Partial Shear Interaction", Journal of Structural Engineering, 1998, Vol. 124, No. 10, pp. 1159-1165.

[21] Ollgaard, J.G., Slutter, R.G. and Fisher, J.W., "Shear Strength of Stud Connectors in Lightweight and Normal Weight Concrete", Engineering Journal of AISC, 1971, Vol. 8, No.2, pp. 55-64.

[22] Ahna, J., Leeb, C., Wona, J. and Kima, S., "Shear Resistance of the Perfobond-rib Shear Connector Depending on Concrete Strength and Rib Arrangement", Journal of Constructional Steel Research, 2010, Vol. 66, No. 10, pp. 1295-1307. 
[23] Al-Darzi, S.Y.K., Chen, A.R. and Liu, Y.Q., "An Experimental Investigation on Stud and Perfobond Connectors with Push-out test", Proceeding of the 13th International Conference on Steel and Composite Structures, UK, 2007, pp. 455-462.

[24] Iwasaki, H., Fujii, K., Fukada, K., Toyota, T. and Nakamura, H., “A Consideration on Slip Test Methods for Perfobond Shear Connector Focusing on Concrete Confinements", 1st International Conference on Advances in Experimental Structural Engineering, 2005. pp. 871-76.

[25] Machacek J, Studnicka J., "Perforated shear connector", Steel and Composite Structures, 2002, Vol.2, No. 1, pp.51-66.

[26] Medberry SB, Shahrooz BM., "Perfobond shear connector for composite construction", AISC Journal, 2002, Vol.1, pp.2-12.

[27] Ushijima Y, Hosaka T, Mitsuki K, Watanabe H, Tachibana Y, Hiragi H., “An experimental study on shear characteristics of perfobond strip and its rational strength equations", International symposium on connections between steel and concrete, 2001, pp.1066-1075.

[28] Valente MIB, Cruz PJS., "Experimental analysis of Perfobond shear connection between steel and lightweight concrete", Journal of Constructional Steel Research, 2004, Vol.60, pp.465-479.

[29] Okada, J., Yoda, T., and Lebet, J.P., "A study of the grouped arrangement of stud connectors on the shear strength", Journal of the Japan Society of Civil Engineers, 2004, Vol.766, pp.81-95. [in Japanese].

[30] DÖRR, K., "Ein Beitrag zur Berechnung von Stahlbetonscheiben unter besonderer Berücksichtigung des Verbundverhaltens", PhD thesis, University of Darmstadt, 1980.

[31] AASHTO., “AASHTO LRFD Bridge Design Specifications”, Washington, DC, 2007.

[32] Lin, W., and Yoda, T., "Mechanical Behaviour of Composite Girders Subjected to Hogging Moment: Experimental Study", Journal of Japan Society of Civil Engineers, 2011, Vol.67, No.3, pp.583-596.

[33] Eurocode 4. Design of composite steel and concrete structures. General rules and rules for buildings, British-Adopted European Standard, 2005.

[34] Ministry of Construction of People's Republic of China, "Code for design of steel structures. GB50017-2003”, China Planning Press, Beijing, 2003. [in Chinese].

[35] CEP-FIP., "Model Code 90, Model Code for Concrete Structures, Comité Euro-International du Béton (CEB) - Fédération Internationale de la Précontrainte (FIP)", Thomas Telford Ltd., London, UK; 1993.

[36] Ministry of Land, Infrastructure, Transport and Tourism, "Standard specification for railway structures", Japan, 2009.

[37] Frosch, R.J., "Another Look at Cracking and Crack Control in Reinforced Concrete", ACI Structural Journal, 1999, Vol.96, No.3, pp.437-442.

[38] Taniguchi, N., Hansaka, M., Koide, N., Ogaki, K., and Saeki, T., "Study of the hybrid structures changed from the steel bridges for railroad which considered construction", Journal of Structural Engineering, JSCE, 2011, Vol.57A, pp.1052-59. [in Japanese].

[39] Kouzuki, T., Tanahashi, A., Taniguchi, N., Ikariyama, H., Yoda., T., "Experimental study of shear connector for negative bending composite girders with the rubber-latex mortar coating", Journal of Structural Engineering, JSCE, 2009, Vol.56A: 1161-68. [in Japanese]. 